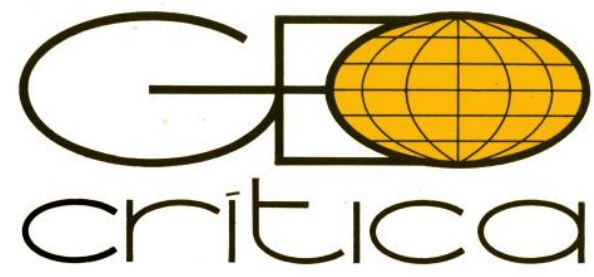

\title{
CAMBIO CLIMÁTICO ANTROPOGÉNICO Y DECRECIMIENTO
}

\author{
Miriam Hermi Zaar \\ Universidad de Barcelona \\ miriamzaar@gmail.com
}

\section{Cambio climático antropogénico y decrecimiento (Resumen)}

El Cambio climático antropogénico ha sido objeto de análisis y debates desde los años 1970. Se ha elaborado un gran número de informes que evidencian sus impactos sobre los ecosistemas y el modo de vida de los seres vivos. Este artículo tiene como objetivo rescatar los principales estudios sobre el cambio climático realizados en los últimos años, señalar los exiguos avances que se han obtenido en las conferencias mundiales y plantear acciones políticas y económicas que impulsen un razonamiento crítico hacia el actual modelo de crecimiento ilimitado. Todo ello con el propósito apremiante de desarrollar vías que conduzcan a un consumo responsable y a un decrecimiento, coherentes con los límites de la biosfera terrestre.

Palabras clave: Cambio Climático Antropogénico; Crecimiento ilimitado; Razonamiento crítico; Vías hacia un decrecimiento económico; Consumo responsable.

\section{Anthropogenic climate change and degrowth (Abstract)}

Anthropogenic Climate Change has been the object of analysis and debate since the 1970s. A large number of reports have been produced that show its impacts on ecosystems and the way of life of living beings. This paper aims to rescue the main studies on climate change carried out in recent years, point out the exiguous advances that have been obtained in world conferences and propose political and economic actions that promote critical reasoning towards the current model of unlimited growth. All this with the urgent purpose of developing ways that lead responsible consumption and a degrowth, coherent with the limits of the terrestrial biosphere.

Key words: Anthropogenic Climate Change; Unlimited growth; Critical thinking; Paths to an economic degrowth; Responsible consumption. 


\section{Introducción}

Según el físico Manuel de Castro Muñoz de Lucas, se entiende por cambio climático antropogénico la alteración que experimentan los diversos climas terrestres por el sobrecalentamiento global, causado por la acumulación en la atmósfera de ciertos gases emitidos con la quema de combustibles fósiles (carbón, petróleo y gas) ${ }^{1}$. A diferencia de las causas naturales, este proceso es resultado de nuestro metabolismo social y sus flujos tienen como consecuencia una gran producción de gases de efecto invernadero ${ }^{2}$.

La primera vez que se consideró el cambio climático antropogénico como una amenaza real para el planeta Tierra fue en 1979, en la Primera Conferencia Mundial sobre el Clima en Ginebra, cuando se adoptó una declaración que exhortaba a los gobiernos a prever y evitar los posibles cambios provocados por el ser humano.

En la década de 1980 el tema ganó notoriedad y hubo varias iniciativas con el objetivo de estudiar el cambio climático. En 1980 se creó el World Climate Research Programme con el propósito de determinar la previsibilidad del clima y la responsabilidad de las actividades humanas en la alteración del mismo ${ }^{3}$.

A continuación, en 1988 se instituyó el Panel Intergubernamental de Expertos sobre el Cambio Climático (IPCC), órgano científico internacional que examina y evalúa la bibliografía científica, técnica y socioeconómica relacionada con el mismo. Hasta 2019 se han publicado cinco informes, el último en 2014. Se prevé que la publicación del Sexto Informe de Evaluación será en 2022, y contribuirá a la elaboración del primer balance mundial de la Convención Marco de las Naciones Unidas sobre el Cambio Climático (CMNUCC) ${ }^{4}$.

Una década más tarde, en 1998, la World Wildlife Fund (WWF) publicó, por primera vez, el Informe Planeta Vivo, con el propósito de estudiar el estado y la evolución de la biodiversidad del planeta. En 2018 publicó su $12^{\mathrm{a}}$ edición. En sus informes se incluye el Índice Planeta Vivo que ha medido el estado de 16.704 poblaciones de 4.005 especies de vertebrados ${ }^{5}$.

En esta misma línea de acción, se fundó, en 2001, el Global Carbón Proyect con el objetivo de trabajar con la comunidad científica internacional y establecer una base de conocimientos común y mutuamente acordada, para asesorar el debate sobre políticas y acciones con la finalidad de frenar el aumento de gases de efecto invernadero en la atmósfera. Este proyecto ha publicado un gran número de investigaciones sobre el incremento de las concentraciones atmosféricas de los principales gases de efecto invernadero: dióxido de carbono $\left(\mathrm{CO}_{2}\right)$, metano $\left(\mathrm{CH}_{4}\right)$ y nitrógeno óxido $\left(\mathrm{N}_{2} \mathrm{O}\right)^{6}$.

\footnotetext{
${ }^{1}$ Manuel de Castro Muñoz de Lucas. El País, 2/12/2015

<https://elpais.com/elpais/2015/12/01/opinion/1448991799_754191.html>.

${ }^{2}$ El metabolismo social comienza cuando los seres humanos socialmente agrupados se apropian de materiales y energías de la naturaleza (input), y finaliza cuando depositan desechos, emanaciones o residuos en los espacios naturales (output). Este proceso está representado por cinco fases apropiación, transformación, circulación, consumo y excreción (Toledo, 2013, p. 47).

${ }_{3}^{3}$ World Climate Research Programme <https://www.wcrp-climate.org/>.

${ }^{4}$ IPCC <https://archive.ipcc.ch/home_languages_main_spanish.shtml >.

5 Índice Planeta Vivo <https://www.wwf.es/nuestro_trabajo_/informe_planeta_vivo/>.

${ }^{6}$ Global Carbón Proyect <https://www.globalcarbonproject.org/about/index.htm>.
} 
En consonancia con estas metas, Emissions Database for Global Atmospheric Research (EDGAR), vinculado a la Unión Europea, publicó en su último informe un estudio sobre la emisión de $\mathrm{CO}^{2}$ y otros gases que están deteriorando nuestra atmósfera, como el dióxido de azufre $\left(\mathrm{SO}_{2}\right)$, el $\mathrm{NO}_{\mathrm{x}}$ (combinación de óxido nítrico-NO- y dióxido de nitrógeno- $\mathrm{NO}_{2}$ ) y midió las partículas en suspensión de menos de 2,5 micras PM2.5, según las regiones del planeta ${ }^{7}$.

En 2010 se fundó la Plataforma Intergubernamental Científico-normativa sobre Biodiversidad y Servicios de los Ecosistemas (IPBES), con el objetivo de reforzar la interfaz científico-política sobre la biodiversidad y los ecosistemas, y de contribuir a su conservación, al bienestar humano $\mathrm{y}$ al desarrollo sostenible ${ }^{8}$. Sus funciones principales consisten en identificar y priorizar la información científica necesaria y catalizar los esfuerzos para generar nuevos conocimientos, realizar evaluaciones regulares de los conocimientos en materia de biodiversidad y servicios de los ecosistemas, servir de apoyo para la elaboración y aplicación de políticas, mediante la identificación de instrumentos y metodologías relevantes, y priorizar las necesidades en materia de creación de capacidades ${ }^{9}$.

Estas entidades científicas e institucionales y un significativo grupo de investigadores involucrados en la cuestión, han divulgado documentos con un gran número de datos y análisis sobre la evolución del cambio climático antropogénico, en gran parte disponibles on line. Este artículo está estructurado en cuatro apartados, elaborados a partir de una exhaustiva revisión bibliográfica y consultas en páginas Web. Inicialmente nos centramos en los estudios sobre el origen y evolución del cambio climático, destacando la trascendental huella ecológica e hídrica que nuestro modelo económico de crecimiento ilimitado nos ha dejado. A continuación, abordamos las diversas consecuencias del cambio climático para los ecosistemas y la biodiversidad del planeta. En un tercer apartado, exponemos los intentos de las Cumbres Mundiales y del Protocolo de Kioto, para establecer un límite a las emisiones de $\mathrm{CO}_{2}$ y los exiguos avances que las mismas han tenido. Finalmente, planteamos, a partir de estudios realizados y experiencias vigentes, propuestas vinculadas a la necesidad de desarrollar estrategias hacia vías para alcanzar el decrecimiento.

\section{Estudios recientes sobre el origen y evolución del cambio climático antropogénico}

Estudios realizados desde la década de 1950 han demostrado que caminamos hacia una crisis medioambiental, proponiendo un conjunto de recomendaciones hacia una sociedad sostenible. Las primeras contribuciones a estos análisis fueron del filósofo Günther Anders (Die Antiquiertheit des Menschen I, 1956), de la teórica política Hannah Arendt (The Human Condition, 1958), del economista rumano Nicholas Georgescu-Roegen (The Entropy law and the Economic Process, 1971) y del Informe Meadows de 1972.

El Informe Meadows, elaborado bajo la responsabilidad de la científica ambiental Donella Meadows y publicado por el Club de Roma (Los límites del crecimiento), fue actualizado en las

\footnotetext{
${ }^{7}$ EDGAR <https://www.eea.europa.eu/themes/air/links/data-sources/emission-database-for-global-atmospheric〉.

${ }^{8}$ Intergovernmental Science-Policy Platform on Biodiversity and Ecosystem Services.

${ }^{9}$ Gobierno de España. Ministerio para la Transición Ecológica

$<$ https://www.miteco.gob.es/es/biodiversidad/temas/conservacion-de-la-biodiversidad/conservacion-de-la-

biodiversidad-en-el-mundo/cb_mundo_plataforma_ipbes.aspx $>$.
} 
décadas siguientes y publicado bajo diferentes denominaciones: Más allá de los límites del crecimiento (1992) y Los límites del crecimiento: 30 años después (2004).

A pesar de éstos y otros estudios divulgados en las últimas décadas, se ha avanzado muy poco con relación a nuestras acciones contra el deterioro medioambiental. En la coyuntura actual, cuyo modelo económico está basado en la explotación ilimitada de los recursos naturales, llevar a cabo medidas para el control de la contaminación y para evitar la destrucción de la naturaleza, puede ser una tarea difícil para gran parte de los gobernantes debido a la gran fluidez y movilidad que el capital ha logrado en las últimas dos décadas, guiado por la financiarización de la economía. Este proceso, en el que los fondos financieros han tenido protagonismo, ha propiciado una creciente autonomización del sector financiero en relación con la producción y ha contribuido al surgimiento de un nuevo patrón de acumulación en el capitalismo contemporáneo.

Para esta gran movilidad o "hipermovilidad"10 del capital han coadyuvado las tecnologías puntas vinculadas a los sistemas informacionales y a las plataformas digitales, que han posibilitado el movimiento trasfronterizo de éste, entre los diferentes sectores económicos y una gran articulación con los poderes políticos locales y regionales. Todo ello en medio de una lógica que articula flujos y fijos (actuaciones territoriales) y que opera simultáneamente en múltiples escalas.

En esta nueva dinámica, una de las estrategias de este nuevo modelo de acumulación capitalista es la creación de una gran necesidad de consumir mediante créditos, "el motor que mantiene la economía en movimiento" "11 y gran generador de plusvalía.

Para esto, se conjugan dos modalidades que impulsan un crecimiento continuo e indiscriminado del consumo, creando necesidades ficticias: la publicidad y la "obsolescencia programada". Como señalan Denis Bayon, Frabrice Flipo y François Schneider, el capitalismo, al orientar nuestro consumo, nos despoja de nuestros deseos auténticos y de nuestras necesidades reales. Los macrosistemas a que estamos sometidos a través de la manipulación publicitaria alteran nuestro modo de vida, substraen nuestras convicciones auténticas y las reemplazan por un imperativo que nos impulsa a cambiar por cambiar y nos convence que 'más' es 'mejor'12.

En la otra punta del proceso de consumo, están las entropías, entendidas como la energía dispersada ante un proceso termodinámico, y el consecuente incremento de la contaminación planetaria que el capital plantea resolver a través de "tecnologías verdes". Su meta es el fomento de nuevas tecnologías y modelos de gestión del proceso de producción y de los recursos, sin que se pierda la monetarización de la naturaleza, y sin que se cuestione el actual modelo de desarrollo productivista-consumista. Todo ello, de acuerdo con lo que David Harvey denomina de "acumulación sinfín".

\section{Las emisiones de $\mathrm{CO}_{2}$ como protagonistas del proceso de cambio climático}

$\mathrm{El}$ incremento de la concentración de $\mathrm{CO}_{2}$ y de otros gases atmosféricos contribuyentes al "efecto invernadero", ha alterado el equilibrio de los ecosistemas mantenido a lo largo de los últimos milenios. Se calcula que este incremento ha sido del $40 \%$ desde mediados del siglo XIX.

\footnotetext{
${ }^{10}$ Harvey, 2014 <https://www.traficantes.net/sites/default/files/pdfs/Diecisiete\%20contradicciones\%20$\% 20$ Traficantes\%20de\%20Sue\%C3\%B1os.pdf $>$.

${ }^{11}$ Pessanha, 2019, p. 30.

${ }^{12}$ Bayon, Flipo, Schneider, 2011, p. 141.
} 
Estas son algunas de las conclusiones a las que se han llegado con los llamados modelos de simulación del clima que reproducen el calentamiento global medio, observado desde el inicio de la era industrial, y realizan predicciones válidas, aunque se alteren las condiciones del sistema al que se aplican.

Al escenario actual han contribuido diversas fases de la industrialización que desde el siglo XIX están 'domesticado la naturaleza' y perfeccionando sus técnicas, para retirar del suelo y del subsuelo ingentes cantidades de materia prima y de fuentes de energía fósil. En este proceso, también se incluyen, por un lado, la urbanización difusa asociada a la especulación inmobiliaria, y por otro, la agricultura industrial, considerada como la única que, por su alta productividad, podría alimentar al mundo. La práctica de esta última implica una gran contradicción, debido al despilfarro de energía y materias primas (carburantes e insumos agrícolas) para producir alimentos cuyas propiedades nutricionales son cuestionables, por el hecho de que el excesivo empleo de abonos e insecticidas destruye la vida microbiana de los suelos y sus nutrientes naturales, empobreciéndolos.

Con relación a la contaminación atmosférica por gases provenientes de combustibles fósiles, el Global Carbón Proyect, publicó en su reciente Atlas (2018) un mapa interactivo que posibilita analizar la evolución de la emisión de gases originados por combustibles fósiles provocado por la actividad humana (carbón, petróleo, gas, gas flaring, cemento) en un gran número de países. En este mapa se observa cómo entre 1960 y 2017 la emisión de $\mathrm{CO}_{2}$ se incrementó en determinadas regiones de América Latina, Asia, Oriente Medio y África. Algunos países pasaron de cuotas insignificantes o muy bajas a proporciones muy elevadas, como es el caso de China e India, aunque también se observa un importante incremento de emisiones de $\mathrm{CO} 2$ en muchos otros países (figura 1).

Figura 1. Emisiones territoriales de $\mathrm{CO}_{2}$ emitidas por actividad humana. Comparación entre 1960 y 2017
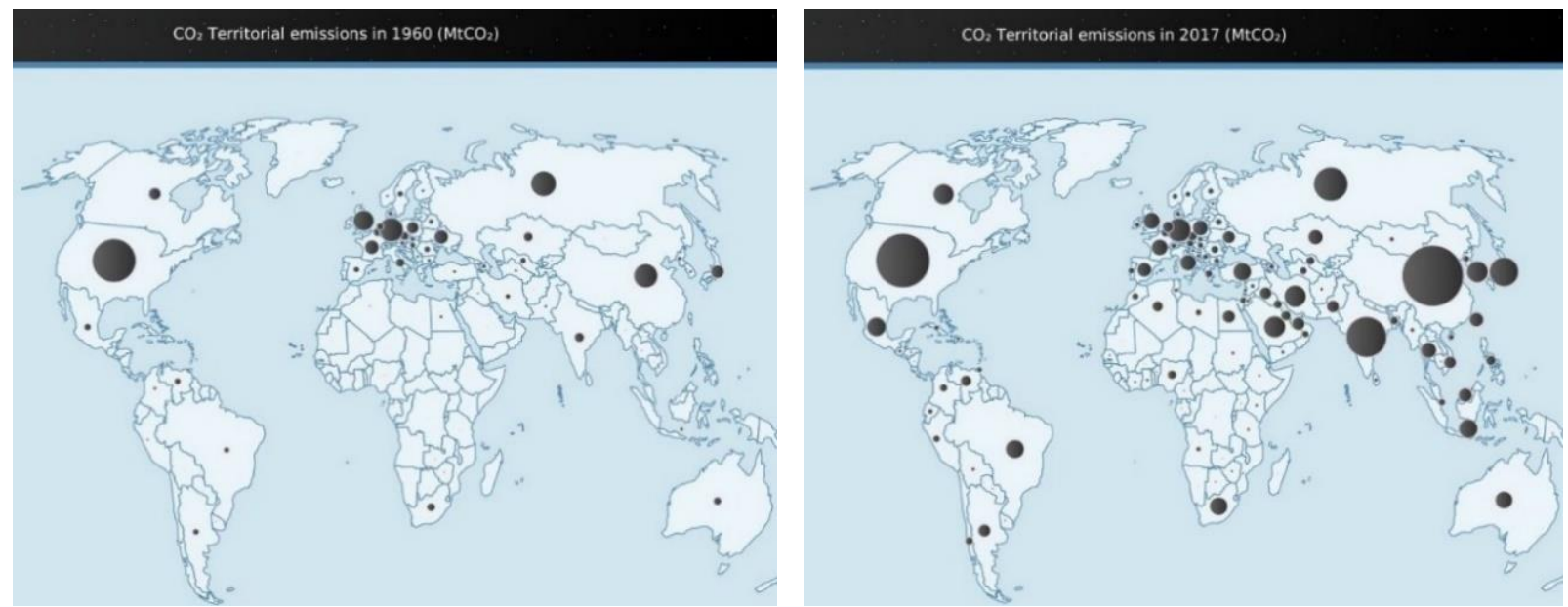

Fuente: Global Carbón Project <http://www.globalcarbonatlas.org/en/content/welcome-carbon-atlas>. Para acceder al grafico interactivo <http://www.globalcarbonatlas.org/en/content/welcome-carbon-atlas >.

A esta configuración han coadyuvado varios factores vinculados a la implantación del paradigma neoliberal, entre ellos la creciente movilidad del capital que impulsó una deslocalización industrial sin precedentes durante la segunda mitad del siglo XX, teniendo como origen Estados Unidos y Europa y como destino países del continente asiático. Como consecuencia, China se ha transformado en el mayor emisor de fósil $\mathrm{CO}_{2}$ con el $27 \%$ del total global, seguido por Estados 
Unidos, responsable de un $15 \%$ del total. Les siguen los países de la Unión Europea con una reducción substancial, aunque todavía generan un 10\%, e India, con un notable incremento en las emisiones de $\mathrm{CO}_{2}$ en los últimos años, produciendo un $7 \%$ del total mundial ${ }^{13}$ (figura 2).

Figura 2. Evolución anual de emisiones de $\mathrm{CO}_{2}$ en gigatoneladas/año

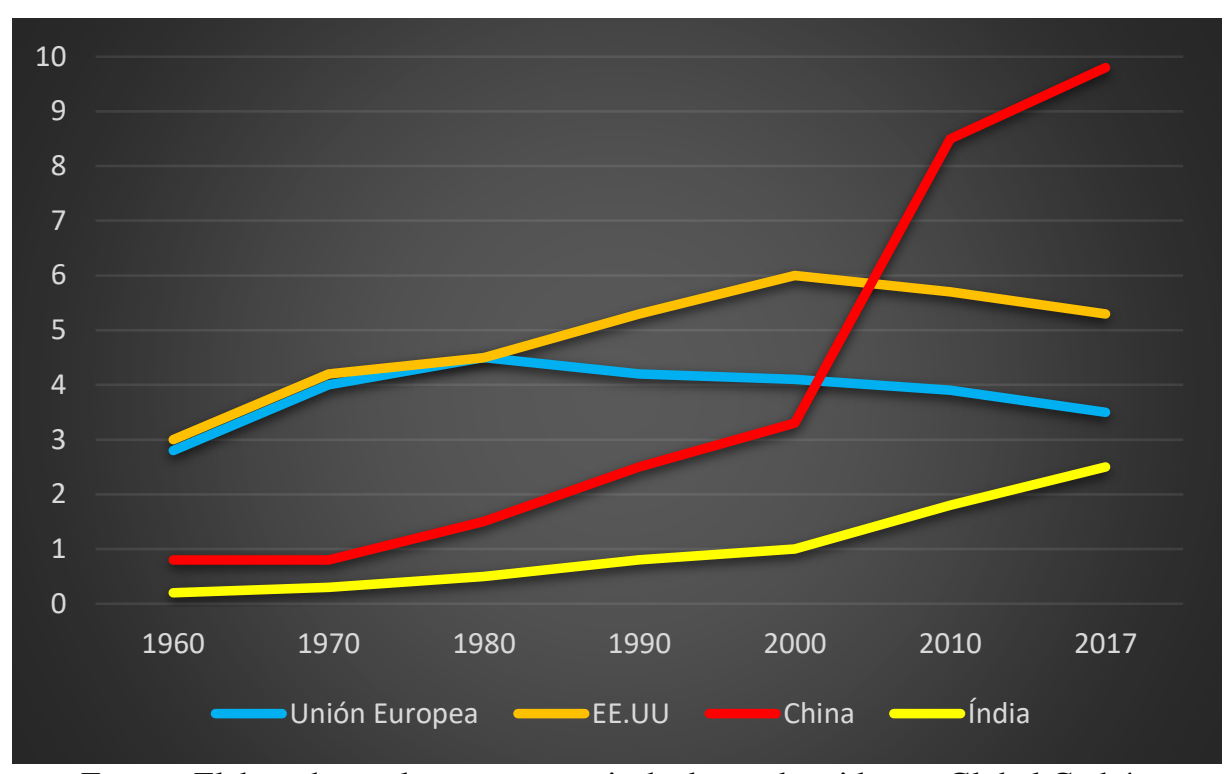

Fuente: Elaborado por la autora a partir de datos obtenidos en Global Carbón

Resultados similares se encuentran en otros estudios como el Emissions Database for Global Atmospheric Research (EDGAR) de la Unión Europea, que en su Informe de 2020 comparó la emisión total de $\mathrm{CO}^{2}$ de 1990 con la de 2019. La Unión Europea y Reino Unido redujeron un 25,1\%, mientras que Estados Unidos y Japón aumentaron sus emisiones en un 0,8 y un 0,4\%, respectivamente. A su vez, las economías emergentes de China e India incrementaron 3,8 y 3,3 veces, respectivamente, sus emisiones de CO2 en 2019 en comparación con 1990.

Si tomamos como base solamente las emisiones en 2018 y 2019, tenemos los siguientes resultados: el mayor aumento relativo se encuentra en China $(+3,4 \%)$, seguido de India $(+1,6 \%)$. Por el contrario, la Unión Europea y Reino Unido (-3,8\%), Estados Unidos (-2,6\%), Japón $(-2,1 \%)$ y Rusia $(-0,8 \%)$ redujeron sus emisiones de $\mathrm{CO} 2$ fósil ${ }^{14}$.

Los sectores que más han contribuido al incremento de $\mathrm{CO}^{2}$ han sido la industria (China), los transportes (India, China, Rusia) y la agricultura (Oceanía, América Latina) (figura 3).

\footnotetext{
${ }^{13}$ Global Carbón Proyect <https://www.globalcarbonproject.org/carbonbudget/>.

${ }^{14}$ European Comission. JCR Science for police report <https://edgar.jrc.ec.europa.eu/booklet2020/Fossil_CO2_emissions_of_all_world_countries_booklet_2020report.pd f>.
} 
Figura 3. Evolución del \% de contribución de diferentes sectores económicos en las emisiones de $\mathrm{CO}^{2}$ por continentes/regiones (1970-2012)
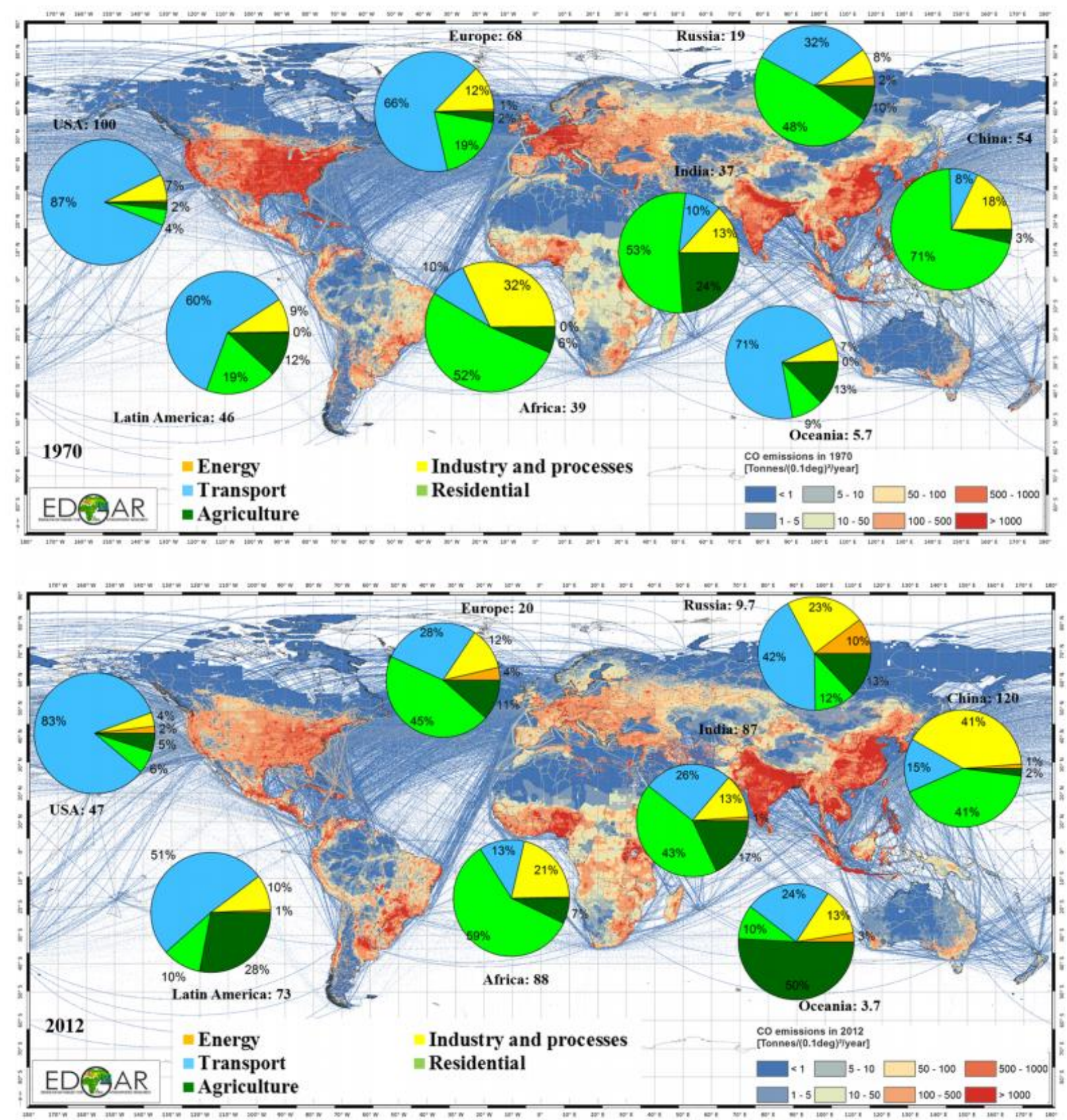

Fuente: M. Crippa et al. Gridded emissions of air pollutants for the period 1970-2012 within EDGAR v4.3.2, 2018 $<$ https://www.earth-syst-sci-data.net/10/1987/2018/>.

M. Crippa et al (2018) en su publicación Gridded emissions of air pollutants for the period 19702012 within EDGAR, elaboraron varios análisis sobre los gases que están deteriorando nuestra atmósfera, como el dióxido de azufre $\left(\mathrm{SO}_{2}\right)$, el $\mathrm{NO}_{\mathrm{x}}$ (combinación de óxido nítrico-NO- y dióxido de nitrógeno- $\mathrm{NO}_{2}$ ), y midieron las partículas en suspensión de menos de 2,5 micras PM2.5).

Con relación al dióxido de azufre $\left(\mathrm{SO}_{2}\right)$ estos autores afirman que, mientras la Unión Europea y EEUU han reducido considerablemente su emisión, en otros países el incremento ha sido importante. Se refieren a China (que pasó de 8,6 Mt año a 32), India (de 1,9 Mt año a 12), África 
(de 2 Mt año a 7) y América Latina (de 3,5 Mt año a 6,1). Sobre el dióxido de nitrógeno $\left(\mathrm{NO}_{\mathrm{x}}\right)$ también destacan una importante alza protagonizada por China (de 3,8 Mt año a 30) y seguida por India (de 2,3 Mt año a 11), África (de 2 Mt año a 5,5) y América Latina (de 3,1 Mt año a 9,7).

Con referencia a las partículas en suspensión de menos de 2,5 micras (PM2.5), M. Crippa et al (2018) compararon datos de 1970 y 2012 y observaron una reducción en Europa (de 3,3 Mt año a 1,5), en EEUU (de 2,6 Mt año a 1,3), en Rusia (de 1,5 Mt año a 0,5) y en China (de 4,7 Mt año a 1,2), y un incremento significativo en India (de 3 Mt año a 7,4), en África (de 2,4 Mt año a 5,7) y en Latinoamérica (de 1,8Mt año a 3,9).

Sus conclusiones son que a las emisiones de estos gases han contribuido, en más del $50 \%$ e incluso un $80 \%$ dependiendo del país o región, la producción de energía $\left(\mathrm{SO}_{2}, \mathrm{CO}^{2}, \mathrm{NO}_{x}\right)$, los transportes $\left(\mathrm{CO}^{2}, \mathrm{NO}_{x}\right)$, la industria y la agricultura $\left(\mathrm{CO}^{2}, \mathrm{NO}_{x}, \mathrm{PM} 2,5\right)$, y el sector residencial $(\mathrm{CO}$, $\mathrm{PM} 2.5)^{15}$.

Las principales fuentes que contribuyeron a la emisión fósil de $\mathrm{CO}_{2}$ en 2017 fueron: carbón (40\%), petróleo $(35 \%)$ gas $(20 \%)$, cemento $(4 \%)$, biomasa (1\%). Los tres mayores emisores de $\mathrm{CO}_{2}$, tuvieron entre 2000 y 2017 tasas de crecimiento global anuales del 2\% en gas, 1,4\% en petróleo y 0,7 en carbón.

A la vez, la energía hidroeléctrica obtuvo, en este mismo período, un crecimiento anual del $2 \%$, que, a pesar de ser considerada una energía renovable, suele ocasionar impactos, tanto a nivel medioambiental, con el desequilibrio del ecosistema y la producción de dióxido de carbono (CO2) y de metano ( $\mathrm{CH} 4)$, cómo social, provocando la desterritorialización de la población local y la perdida de sus referencias sociales, económicas y espaciales, por su desplazamiento forzoso hacia otras áreas, como analizan varios autores, entre ellos Philip Fearnside y Salvador Pueyo (2012) y Miriam Zaar (2019b). Las conclusiones de Philip Fearnside señalan que hay evidencias sustanciales de que las presas, principalmente las situadas en zonas tropicales, emiten cantidades significativas de gases de efecto invernadero ${ }^{16}$.

También se ha de destacar un incremento muy importante $(13,9 \%)$ de las energías limpias como la solar, la eólica, etc., aunque todavía representan muy poco en relación al conjunto de energía consumida globalmente ${ }^{17}$.

Otro aspecto a subrayar es el impacto generado por el actual sistema de transporte, fomentado por un modelo económico que organiza y segrega los territorios en áreas de producción y áreas de consumo a escala intercontinental. Para su articulación se establecen intensos flujos de mercancías, y también de servicios y personas, que forman extensas rutas con grandes emisiones de $\mathrm{CO}_{2}$. En esta operación intercontinental, las exportaciones chinas son las responsables de los mayores flujos de mercancías y consecuentemente, las mayores emisiones de $\mathrm{CO}_{2}$, mientras los EUA, Rusia y Europa le siguen, aunque a gran distancia (figura 4).

\footnotetext{
${ }^{15}$ M. Crippa et al, 2018 < https://www.earth-syst-sci-data.net/10/1987/2018/>.

${ }^{16}$ Fearnside et al 2012, p. 221-226

<https://www.researchgate.net/publication/283153785_Subestimacao_das_emissoes_de_gases_de_efeito_estufa_de _represas_tropicais/link/562d6e5108ae518e34824bf7/download $>$.

${ }^{17}$ Global Carbon Budget, 2019 <https://www.globalcarbonproject.org/carbonbudget/archive.htm>.
} 
Figura 4. Mayores flujos globales de importación y exportación en 2012 y las emisiones de $\mathrm{CO}_{2}$. Unidades: $\mathrm{MtCO}_{2}$

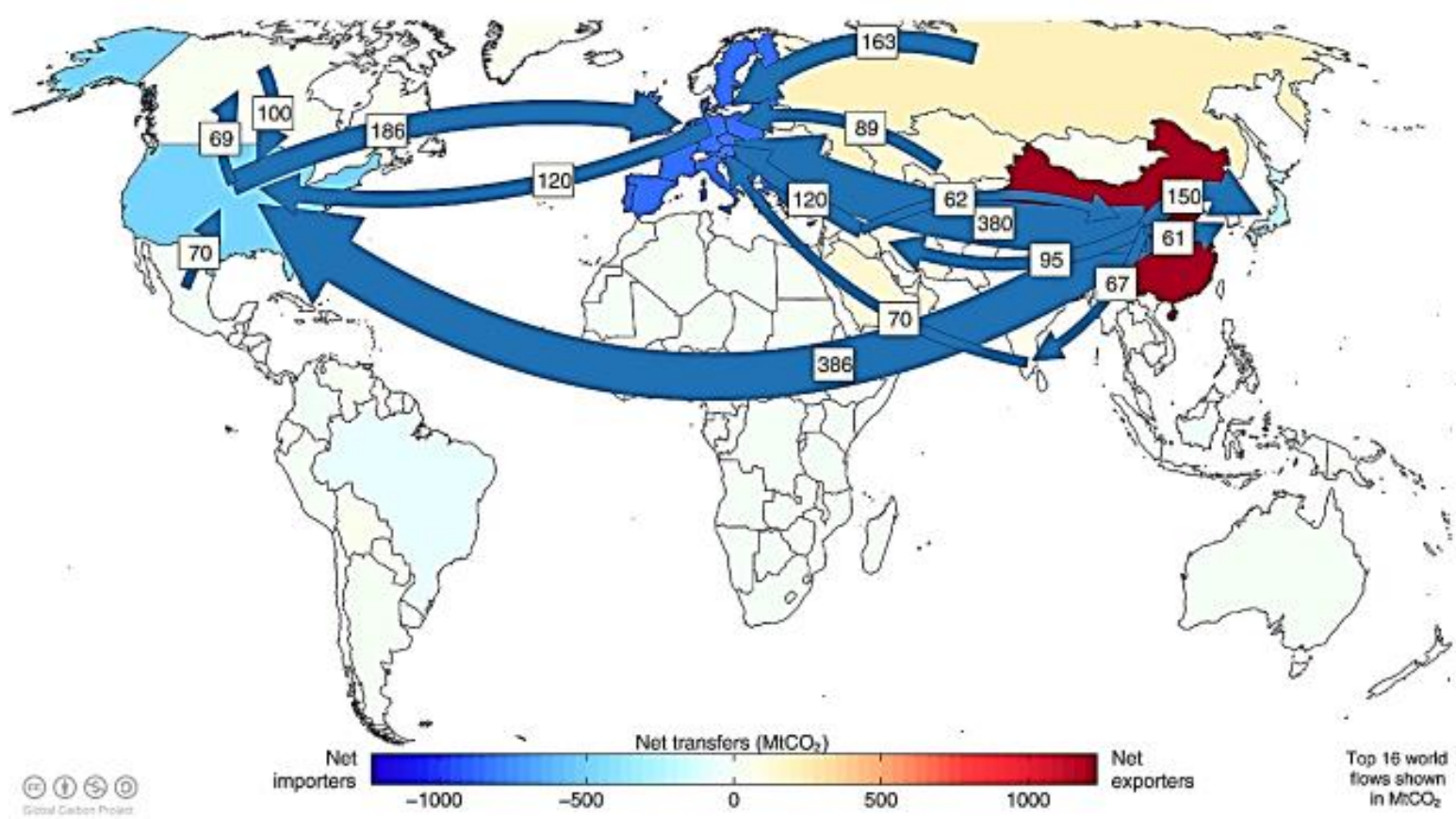

Fuente: Globalcarbonproject 2019 < https://www.globalcarbonproject.org/carbonbudget/archive.htm>.

Con relación a 2020, según Global Carbón Budget 2020, los datos preliminares de los cambios en las emisiones estiman una disminución aproximada del 7\% en relación con 2019 (estimación mediana). Las restricciones implementadas debido a la COVID-19 llevaron a una disminución en la producción, en la exportación y en el consumo sin precedentes, lo que provocó una reducción significativa en las emisiones de CO2 en todos los países ${ }^{18}$.

\section{El actual modelo económico y su huella ecológica}

La huella ecológica es un mecanismo que evalúa nuestro metabolismo socioeconómico. Fue elaborada y presentada por primera vez por William Rees y Marthis Wackernagel en la University of British in Columbia en 1994. Su objetivo es valorar el impacto humano, derivado del consumo de recursos naturales (a través de cultivos, pastoreo, suelo urbanizado, zonas pesqueras, áreas de bosques para absorber las emisiones de $\mathrm{CO}_{2}$ ) y de la consecuente deposición de residuos en un determinado territorio, comparado con la biocapacidad de este mismo territorio. Es decir, estudiar su capacidad para proveer los recursos y, al mismo tiempo, para absorber sus residuos.

De este modo "la huella ecológica de una población equivale al área biológicamente productiva requerida para producir los recursos utilizados y absorber los residuos generados por dicha población"19.

Con la intensificación del proceso de globalización, el cálculo de la huella ecológica planetaria ha adquirido una mayor relevancia. Para que pudiéramos vivir con los recursos de que dispone

\footnotetext{
${ }^{18}$ Friedlingstein, $2020<$ https://essd.copernicus.org/articles/12/3269/2020/>.

${ }^{19}$ Wackernagel et al., 1999 <http://metagraphies.org/Sir-Patrick-Geddes/ecology/Wackernagel_National.pdf>.
} 
nuestro planeta, la huella ecológica de cada persona debería ser igual a la biocapacidad del mismo, estimada en 1,7 hectáreas globales (hag) ${ }^{20}$.

Sin embargo, en consecuencia del proceso de hiperconsumo y de degradación medioambiental, en 2018 se habría necesitado, de media, la biocapacidad de 1,7 planetas para suministrar los recursos naturales y prestar los servicios que la Humanidad consumió ese año. Esto se debe al hecho que, mientras en algunos países africanos y asiáticos la huella ecológica por habitante es menor que 1,7 ha., en Europa es superior a los 3,4 ha., y en otros como EUA, Canadá y Australia rebasa a los 6.7 ha. (figura 5).

Figura 5. Huella ecológica por persona, según la población de los países (en hectáreas globales)

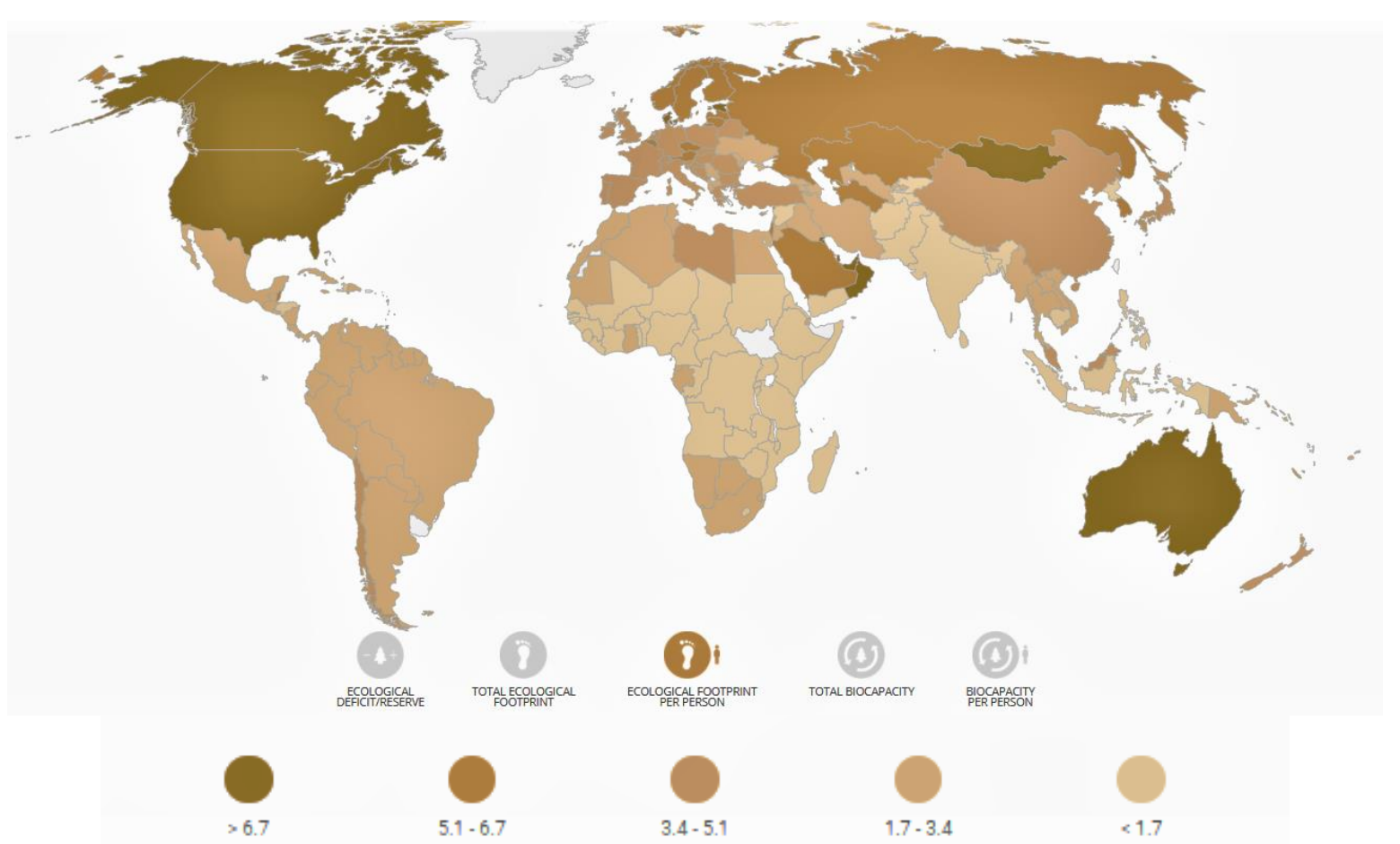

Fuente: Elaborado por la autora a partir de Global Footprint Network, $2021<$ https://www.footprintnetwork.org/>

En esta coyuntura estamos mermando el capital natural a mayor velocidad de la que necesita para regenerarse. En consecuencia, los recursos planetarios se tornan cada vez más escasos, y a la vez, la entropía se incrementa a un ritmo acelerado.

Asimismo, existen otras metodologías que evalúan nuestro metabolismo socioeconómico. La "huella hídrica" como un indicador del "volumen total de agua utilizada para producir los bienes y servicios consumidos por un individuo, por un grupo de personas o por un país" ${ }^{21}$, es una de ellas, y para su análisis se clasifican las fuentes de agua, en agua azul, agua verde y agua gris. La huella hídrica azul se refiere al volumen de agua dulce (superficial o subterránea) consumida incorporándola a la cadena de producción; la huella hídrica verde es el volumen de agua de la lluvia que se almacena en el suelo y en la vegetación, y que se evapora; y, la huella hídrica gris es

\footnotetext{
${ }^{20}$ La hectárea global (hag) es una medida empleada para calcular la media de la bioproductividad de la Tierra. La obtenemos sumando todas las hectáreas consideradas "productivas" y dividiendo el total por el número de habitantes del planeta.

${ }^{21}$ Chapagain y Hoekstra, 2004, Hoekstra, 2003

<https://ris.utwente.nl/ws/portalfiles/portal/5132515/Report16Vol1MainReport.pdf>.
} 
el volumen de agua necesaria para diluir los contaminantes liberados en el proceso de producción (vertidos), por lo tanto, es agua contaminada.

Cerca del 92\% de la huella hídrica está vinculado al consumo de productos agrícolas, el 5\% al consumo de bienes industriales y el $4 \%$ al uso doméstico del agua. El consumo de cereales representa la mayor contribución a la huella hídrica del consumidor con un promedio del $27 \%$, seguido de la carne (22\%) y los productos lácteos (7\%). Además, aproximadamente una quinta parte de la huella hídrica mundial se relaciona con la producción para la exportación ${ }^{22}$.

En su conjunto, estos índices nos indican que estamos debilitando nuestro entorno y, por ende, nuestro planeta, cuyas principales consecuencias relacionadas con el deterioro de los ecosistemas y de la reducción de la biodiversidad, abordamos a continuación.

\section{Cambio climático, ecosistemas y biodiversidad planetaria}

El Panel Intergubernamental de Expertos sobre el Cambio Climático (IPCC), en su Quinto Informe (2014), expuso algunos de los resultados de la evolución del cambio climático en las últimas décadas ${ }^{23}$.

Un de ellos es que el calentamiento del sistema climático desde la década de 1950 no tiene precedentes durante siglos o milenios. El período comprendido entre 1983 y 2012 correspondió a las tres décadas más cálidas de los últimos 140 años (figura 6).

En este proceso, el océano fue el protagonista representando más del 90\% de la energía acumulada entre 1971 y 2010. A escala global, el calentamiento del océano es mayor cerca de la superficie, y los $75 \mathrm{~m}$ superiores se calentaron, de media, durante el período 1971 a 2010 , un $0.11^{\circ} \mathrm{C}$ por década.

Además, desde el comienzo de la era industrial, la absorción oceánica de $\mathrm{CO}_{2}$ ha dado como resultado su acidificación. El $\mathrm{pH}$ del agua superficial del océano ha disminuido un 0.1 , lo que corresponde a un aumento del $26 \%$ en su la acidez, medida como la concentración de iones de hidrógeno ${ }^{24}$.

22 UNESCO-IHE. Institute for Water Education, $2011<\mathrm{https} / / /$ waterfootprint.org/media/downloads/Report50NationalWaterFootprints-Vol1.pdf $>$.

${ }^{23}$ IPCC <https://archive.ipcc.ch/home_languages_main_spanish.shtml>.

${ }^{24}$ IPCC <https://ar5-syr.ipcc.ch/topic_summary.php>. 
Figura 6. Evolución de las temperaturas anómalas sobre la superficie terrestre y sobre el Océano

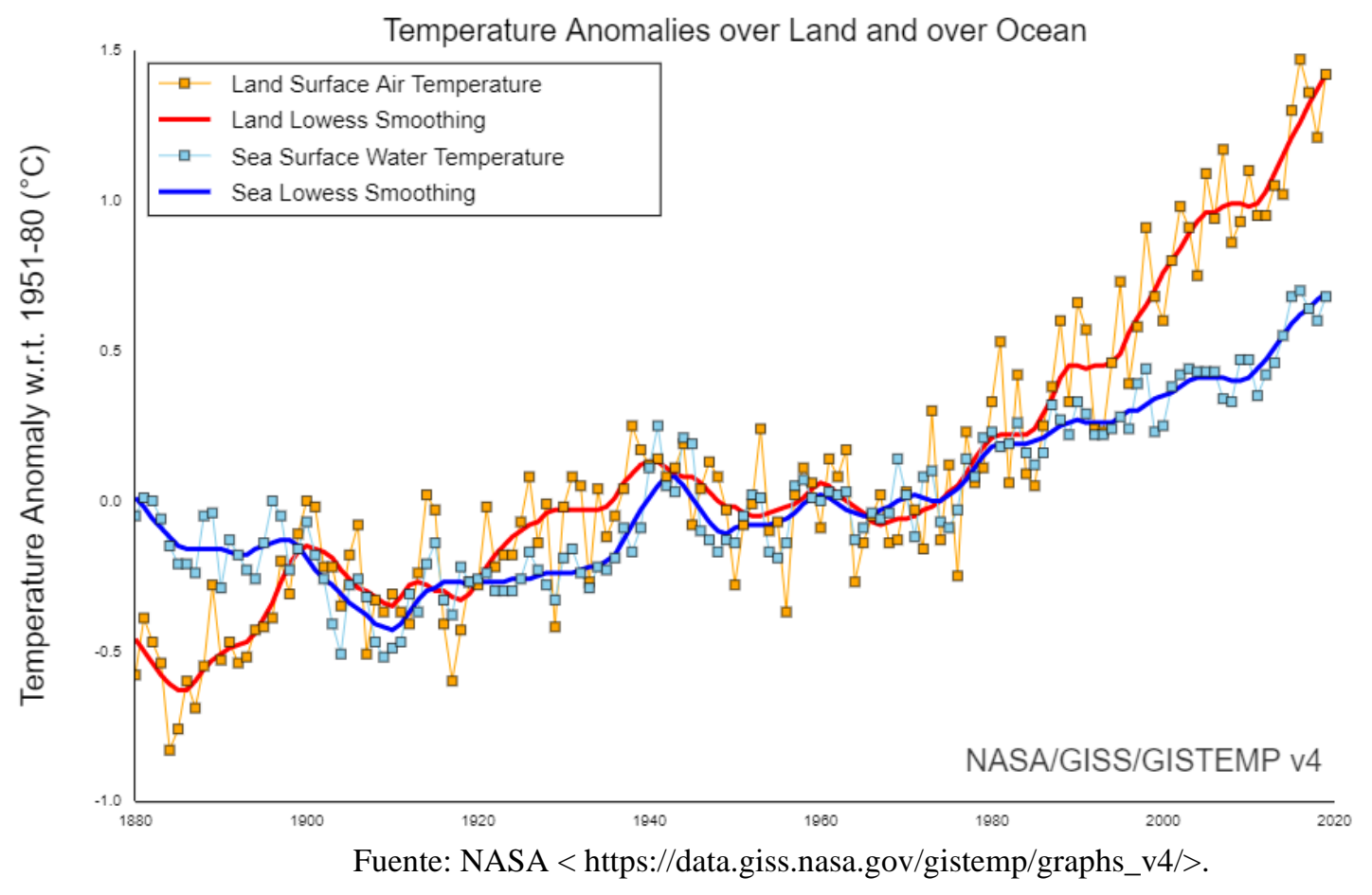

Según estudios realizados por Global Temperature Report for 2019, esta anomalía térmica no se produce homogéneamente, afectando más a unas regiones que a otras (figura 7).

Figura 7. Incremento de las temperaturas en 2019 en relación a la temperatura promedio entre 1951-1980

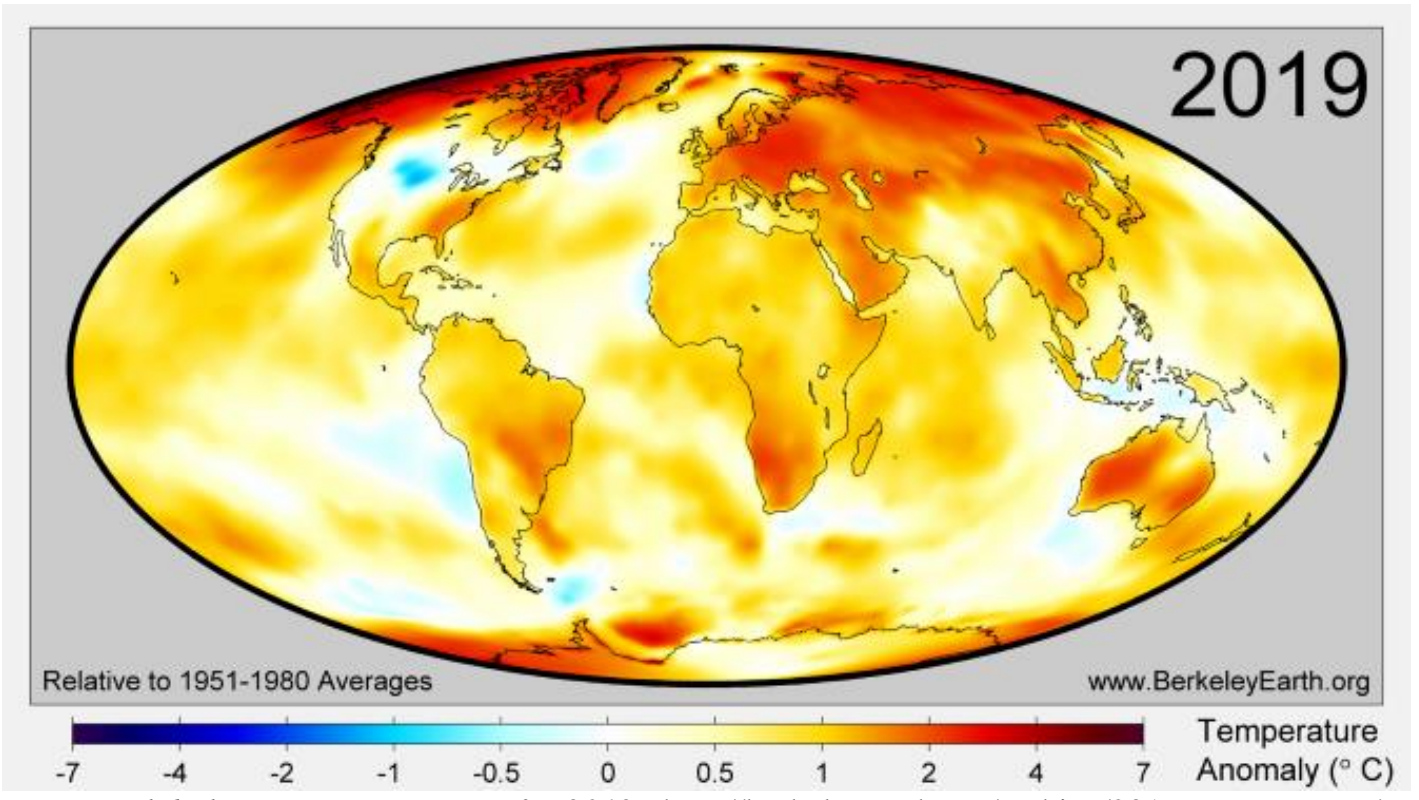

Fuente: Global Temperature Report for $2019<$ http://berkeleyearth.org/archive/2019-temperatures/>. 
Otro aspecto a considerar en este Quinto Informe es que el calentamiento de las superficies terrestres y oceánicas ha ocasionado una significativa pérdida de la masa de hielo y de nieve en Groenlandia y en Antártida entre 1992 y 2011. Los glaciares de casi todo el mundo ${ }^{25}$ y la capa de nieve primaveral del hemisferio norte han disminuido en extensión desde principios de la década de 1980, la última debido al aumento de las temperaturas del permafrost, en respuesta al cambio de la capa de nieve ${ }^{26}$.

La extensión media anual del hielo marino del Ártico disminuyó durante el período 1979-2012, en un rango de 3,5 a 4,1\% por década (figura 8), mientras que la capa de hielo de la región Este de Antártida ha perdido hasta 7 milímetros entre 1995 y 2017.

Figura 8. Ártico. Disminución del volumen de hielo entre 1990 y 2016

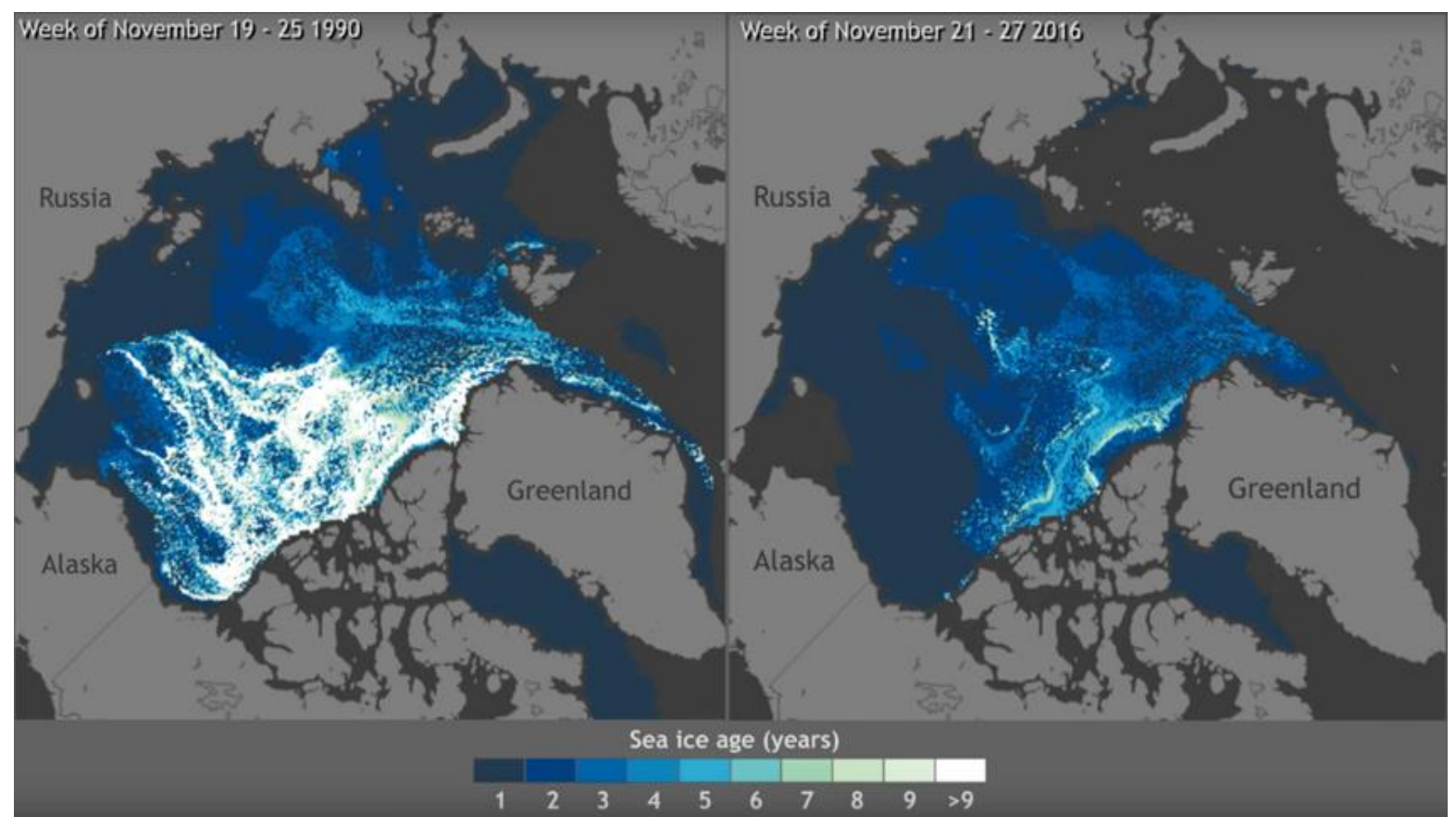

Fuente: National Geographic España <https://www.nationalgeographic.com.es/ciencia/actualidad/formas-vercomo-cambio-climatico-amenaza-artico_11272/1>.

Como consecuencia de este proceso, el incremento del nivel del mar desde mediados del siglo XIX ha sido mayor que la tasa promedio durante los dos milenios anteriores. Durante el período 1901-2010, el nivel medio global del mar aumentó en $0,19 \mathrm{~m}$., y podría alcanzar, durante la segunda mitad del siglo XXI, un incremento de 2,6 milímetros/año, hasta llegar a 1,2 metros en 2100, lo que aumentaría los riesgos de inundación en grandes metrópolis costeras, en puertos y otras zonas marítimas ${ }^{27}$.

\footnotetext{
${ }^{25}$ En agosto de 2019, Islandia puso una placa conmemorativa a su glacial Okjokull, que perdió su rango devorado por el calentamiento global. Muchos otros glaciales se encuentran en este mismo proceso de retroceso por el mismo motivo. En la Antártida, la temperatura en el mes de febrero de 2020 alcanzó un nuevo récord: $18,3^{\circ} \mathrm{C}$ que bate el anterior de $17,5^{\circ} \mathrm{C}$ (marzo de 2015 ).

${ }^{26}$ Quinto Informe de Evaluación (AR5) del IPCC < https://www.miteco.gob.es/es/ceneam/recursos/mini-portalestematicos/Cclimatico/informe_ipcc.aspx >.

${ }^{27}$ Ibidem.
} 
Hay evidencias de que los impactos del cambio climático son más fuertes en los sistemas naturales, aunque también se observan en los sistemas humanos. Con relación al ecosistema, el cambio del índice pluviométrico, el derretimiento de la nieve y del hielo en muchas regiones, está alterando los sistemas hidrológicos, afectando a los recursos hídricos en términos de cantidad y calidad. Muchas especies terrestres de agua dulce y marina han cambiado sus condiciones geográficas, sus actividades estacionales, sus patrones de migración y su abundancia e interacción entre especies, en respuesta al cambio climático en curso $^{28}$.

La Plataforma Intergubernamental sobre Biodiversidad y Servicios Ecosistémicos (IPBES), publicó en marzo de 2018 que la capacidad de la naturaleza para suplir la creciente demanda de productos y la diversidad biológica se está reduciendo en todas las regiones del globo, a causa de la sobreexplotación de los recursos naturales, de la contaminación del aire, de la tierra y del agua, y del incremento de especies exóticas invasoras. Impactos que, asociados, producen e impulsan el cambio climático ${ }^{29}$.

Una de las mayores amenazas a la biodiversidad biológica es la degradación e incluso la destrucción de los bosques, en cuyo interior conviven más del 80\% de las especies terrestres de animales, plantas e insectos. Las principales causas son la agricultura basada en la utilización de agrotóxicos y otras sustancias químicas, la explotación insostenible de la madera y de la minería, los proyectos de infraestructuras, así como el incremento de la incidencia e intensidad de los incendios ${ }^{30}$.

En esta misma dirección, el Living Planet Index (LPI) o Índice Paneta Vivo (IPV), un indicador del estado de la biodiversidad global y de la salud de nuestro planeta, que contiene información de más de 22.000 poblaciones de mamíferos, aves, peces, reptiles y anfibios subraya que, entre 1970 y 2014 la abundancia de las poblaciones de animales vertebrados disminuyó un 60\%, principalmente debido a la degradación de su hábitat. Este índice indica que la región tropical (Neotropical) que comprende América del Sur y Centroamérica es la que ha sufrido la disminución más drástica de especies terrestres y fluviales, el 89\% en comparación con 1970. Le siguen la región Indo-Pacífico con el $64 \%$ de pérdida de su biodiversidad, África Tropical con un $56 \%$, el Paleártico con un $31 \%$ y el Neártico con un $23 \%$ de reducción de sus especies autóctonas $(\text { Cuadro } 1)^{31}$.

\footnotetext{
${ }^{28}$ IPPC <https://ar5-syr.ipcc.ch/topic_summary.php>.

${ }^{29}$ IPBES <http://www.creaf.uab.cat/fotosprensa/Nota_Premsa_IPBES_2018.pdf >.

${ }^{30}$ Informe Planeta Vivo 2018

<http://awsassets.wwf.es/downloads/informe_planeta_vivo_2018.pdf?_ga=2.80222672.699498645.1563707033-

$1726489900.1561834853>$.

${ }^{31}$ Ibidem.
} 
En 2.417 poblaciones terrestres y de água dulce (877 espécies) hubo una reducción de un $23 \%$ entre 1970 y 2014

\section{NEOTROPICAL}

En 1.040 poblaciones (689 especies) se observó una disminución de un 4,8\% al año, representando una disminución total de un $89 \%$ entre 1970 y 2014. Es el cambio más grave de todos los reinos biogeográficos.

\section{PALEÁRTICO}

En 2.866 poblaciones terrestres y de agua dulce (576 especies) se verificó una reducción del 31\% entre 1970 y 2014.

\section{ÁFRICA TROPICAL}

En 115 poblaciones terrestres y de água dulce (320 espécies) se demostró que hubo una reducción de un $56 \%$ entre 1970 y 2014, muy marcada durante la década de 1980.

\section{ÍNDO-PACÍFICO}

En 1.083 pobaciones terrestres y de água dulce ( 488 especies) se comprobó una disminución de un $64 \%$ entre 1970 y 2014.
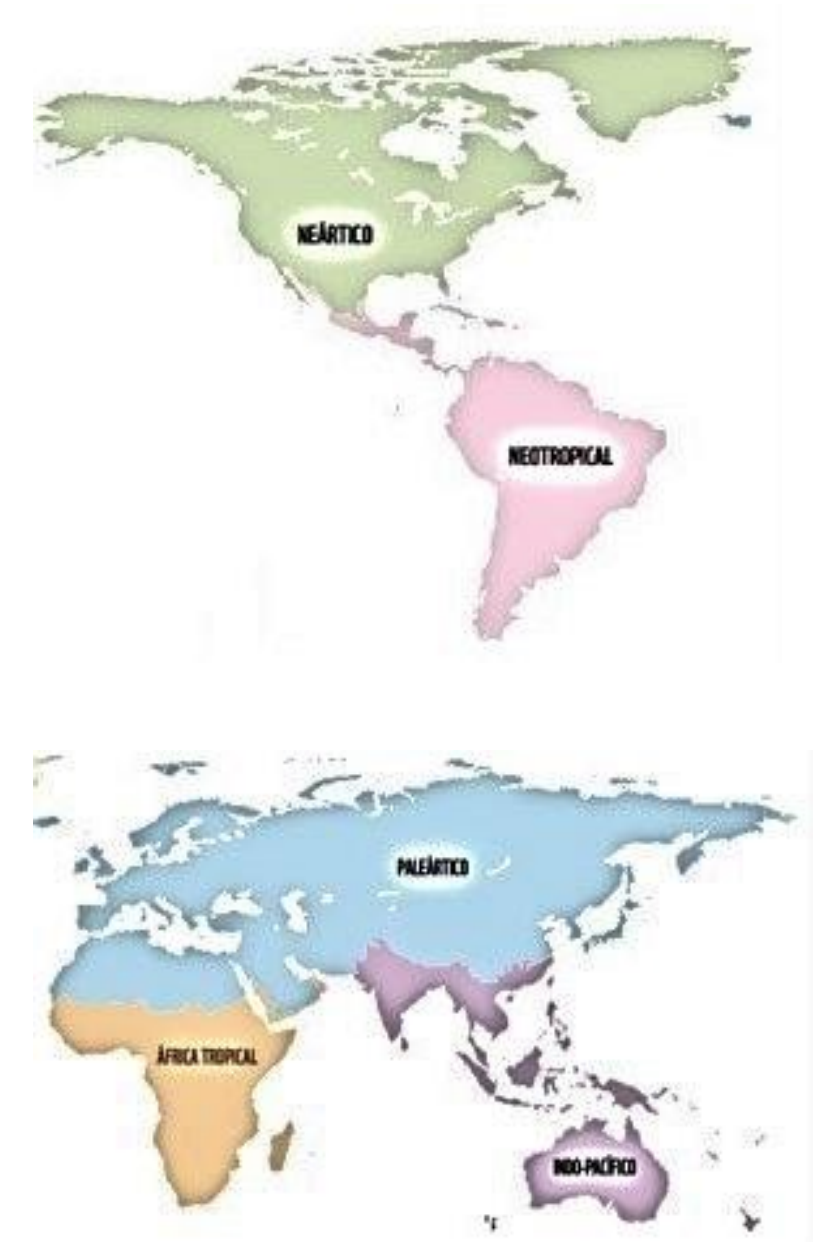

Fuente: Elaborado por la autora a partir de datos del Índice de Planeta Vivo.

<http://awsassets.wwf.es/downloads/informe_planeta_vivo_2018.pdf?_ga=2.80222672.699498645.1563707033$1726489900.1561834853>$.

Estamos ante un modelo de desarrollo, en el que la producción y el consumo, además de haber acelerado la explotación intensiva y el agotamiento de muchos recursos naturales esenciales, ha acarreado efectos perniciosos, como la contaminación sin límites del aire, del agua y del suelo, como consecuencia de la entropía industrial y del uso abusivo de agrotóxicos, etc. ${ }^{32}$.

En su conjunto se trata de un deterioro medioambiental sin parangón, que ha provocado un aumento del índice de $\mathrm{CO}^{2}$, la alteración de los ecosistemas, el cambio climático, la pérdida de la biodiversidad, de gran parte del suelo fértil y consecuentemente, de la soberanía alimentaria ${ }^{33}$,

\footnotetext{
${ }^{32}$ Zaar, 2018, p. 2 <http://www.ub.edu/geocrit/Sociedad-postcapitalista/MiriamZaar.pdf >.

${ }^{33}$ Soberanía alimentaria es la capacidad de cada pueblo para definir sus propias políticas alimentarias agrarias de acuerdo con objetivos que posibiliten su mantenimiento dentro de un marco que respecte el ecosistema, lo que Ignacy Sachs, 2000, definió como 'desarrollo sostenible'.
} 
hasta el punto que, si la economía mundial tal como está estructurada, continúa su expansión, destruirá el medio físico sobre el que se sustenta y se hundirá, como afirma Jered Diamond (2005).

Hay muchos datos que muestran que estamos al límite. Vimos cómo las principales causas de que China se haya transformado en la cuna de importantes epidemias y de la pandemia del SARSCoV-2 están vinculadas no solo a los hábitos chinos de consumir y comercializar animales salvajes, sino también a la destrucción medioambiental. Su rápido proceso de urbanización (más de 200 millones de personas se trasladaron del área rural a la urbana, en las últimas décadas) impulsó la devastación de varios ecosistemas (florestas y otros espacios naturales), lo que trajo como consecuencia la extinción de varias especies animales (y vegetales) y el cambio de hábitos de otras, con una mayor aproximación a las poblaciones y a los animales domésticos, lo que ha aumentado la interacción entre las especies salvajes (que a menudo albergan virus) y los humanos.

Para Manuel de Castro, la magnitud de las futuras alteraciones del clima global está condicionada al ritmo con que sigamos consumiendo combustibles fósiles, y sus consecuencias sólo podrían mitigarse acordando políticas que aminoren progresivamente sus causas. Debido a esto urge fijar un objetivo global cuantificable y evaluable para evitar que el cambio climático alcance un "nivel peligroso" 34 .

Estos son los motivos por los que urge pensar en medidas globales que detengan la emisión de gases responsables del cambio climático, e incluso puedan favorecer su involución. Es lo que se ha intentado en las Cumbres Climáticas Internacionales en las que, basándose en estudios e investigaciones que demuestran que el cambio climático es un hecho, se busca sensibilizar a los gobernantes para que firmen y cumplan los acuerdos debatidos y pactados durante las mismas.

\section{Las cumbres mundiales y sus exiguos avances}

Frente a este acelerado proceso de degradación medioambiental planetaria, se han levantado muchas voces de científicos, ecologistas y de una población cada vez más concienciada, preocupados con el futuro de nuestro planeta y de las próximas generaciones que lo habitarán.

Esta creciente preocupación y la búsqueda de alternativas a la contaminación y sus efectos, como el calentamiento global, ha impulsado varias conferencias mundiales que han abordado la problemática sobre el cambio climático. En la década de 1990 se realizaron la Conferencia de las Naciones Unidas sobre el Medio Ambiente y el Desarrollo en Rio de Janeiro (1992) y la Primera Conferencia de las Partes (delegaciones de países) en Berlín (1995).

Sin embargo, fue en 1997, con el Protocolo de Kyoto, cuando se consiguió el primer acuerdo internacional en el que los países industrializados firmaron compromisos concretos y establecieron un calendario de actuación. Se logró un acuerdo vinculante con todos los países firmantes para que entre 2008 y 2012 se redujesen las emisiones de los seis gases que más potencian el efecto invernadero en un 5,2\%, respecto a 1990.

El siguiente paso fue ampliar los participantes en las cumbres. En la Cumbre de la Tierra de Johannesburgo en (2002), se incluyeron por primera vez, además de jefes de Estado,

\footnotetext{
${ }^{34}$ Muñoz de Lucas. El País, 2/12/2015 <https://elpais.com/elpais/2015/12/01/opinion/1448991799_754191.html>.
} 
representantes de la sociedad civil: Organizaciones no Gubernamentales y otras agrupaciones comprometidas con esta cuestión, delegaciones, periodistas etc.

Las cumbres que la siguieron en Bali (2007), Copenhague (2009), Cancún (2010), Durban (2011), Doha (2012), Varsovia (2013) y Lima (2014) además de constatar el incumplimiento de lo previsto en el protocolo de Kioto, fijaron nuevas hojas de ruta. En Bali se trazó un acuerdo para post 2012, centrándose en lograr una visión común para financiar y adoptar tecnologías que mitiguen la contaminación planetaria; y en Copenhague se acordó fijar el incremento de la temperatura media global hasta el final del siglo XXI, en menos de $2^{\circ} \mathrm{C}$ por cima de los niveles pré-industriales.

En la Cumbre Climática de Cancún (2010), se creó el Fondo Verde para el Clima para proveer financiación a proyectos y actividades en países en desarrollo, y se estableció la activación de un mecanismo tecnológico para promover la innovación, el desarrollo y la difusión de tecnologías amigables al clima ${ }^{35}$.

En la Cumbre de Durban (2011) se hizo hincapié en que las naciones industrializadas redujesen sus emisiones, y en Doha (2012) se concluyó con una resolución que alargó hasta 2020 el periodo de compromiso del Protocolo de Kioto, pero algunos países como EEUU, China, Rusia, Japón o Canadá no la firmaron.

Las Cumbres de Varsovia (2013) y de Lima (2014) se cerraron con acuerdos mínimos y de última hora. La primera, lo hizo activando las ayudas a los países más vulnerables al cambio climático.

En consonancia con las propuestas de las Cumbres anteriores, en la XXI Conferencia Internacional sobre Cambio Climático (2015), también denominada $21^{\mathrm{a}}$ Conferencia de las Partes (COP21-CMP11), todos los países participantes, a excepción de los Estados Unidos, firmaron el Acuerdo de París que a partir de 2020 sustituyó el Protocolo de Kioto. Estos son las principales metas acordadas por los gobiernos:

a) Mantener el aumento de la temperatura media mundial muy por debajo de $2^{\circ} \mathrm{C}$ sobre los niveles preindustriales y proseguir los esfuerzos para limitarlo a $1,5^{\circ} \mathrm{C}$, reconociendo que ello reduciría considerablemente los riesgos y los efectos del cambio climático;

b) Reforzar la capacidad de adaptación de la sociedad para afrontar las consecuencias del cambio climático, promoviendo un desarrollo con bajas emisiones de gases de efecto invernadero;

c) Admiten la necesidad de una cooperación regional y global para reducir las emisiones e incrementar la resiliencia en las áreas más afectadas ${ }^{36}$.

Además del Acuerdo de París, la Agenda 2030 también nos brinda con herramientas para enfrentar los desafíos planteados por el cambio climático, la pobreza y la desigualdad. El documento de la agenda mundial Transformar nuestro mundo: la Agenda 2030 para el Desarrollo Sostenible (Agenda 2030) establece 17 objetivos y 169 metas conexas de carácter integrado e indivisible a través de los cuales se pretende estimular acciones públicas en ámbitos considerados

\footnotetext{
${ }^{35}$ Vengoechea <https://library.fes.de/pdf-files/bueros/la-energiayclima/09155.pdf >.

${ }^{36}$ Comisión Europea. Acción por el Clima <https://ec.europa.eu/clima/policies/international/negotiations/paris_es >.
} 
críticos para la humanidad y para el planeta ${ }^{37}$ y superar procesos que pongan trabas al desarrollo social, que tengan en cuenta la inclusión social y la protección medioambiental ${ }^{38}$.

En 2017, la Cumbre del Clima de Bonn puso en marcha el denominado Diálogo de Talanoa de 2018, que creó un espacio inclusivo y receptivo de intercambio de informaciones y experiencias, con el objetivo de encontrar alternativas para una salida al calentamiento global.

A su vez, la Cumbre del Clima celebrada en Madrid a finales de 2019 (COP25), concluyó con la firma del acuerdo Chile-Madrid. Tiempo de Actuar. Concebido como una manera de despejar el camino para que los países participantes presenten, antes de la Cumbre del Clima de Glasgow (COP26) aplazada para noviembre de 2021 debido a la Covid-19, planes de acción más ambiciosos para combatir la emergencia climática.

Este acuerdo demanda un mayor compromiso de los gobiernos en la elaboración de políticas que fomenten la reducción de las emisiones de gases de efecto invernadero y otras medidas que incrementen la lucha contra el cambio climático. Además, determina que el conocimiento científico sea el eje principal que oriente las decisiones gubernamentales, y que la acción climática debe ser permanentemente actualizada en base a los avances de la Ciencia. De este modo, se reconoce el papel del Panel Intergubernamental de Expertos sobre Cambio Climático (IPCC) para proveer a los países de un mejor conocimiento mediante el que puedan reforzar su capacidad de respuesta ante esta emergencia climática.

Los países firmantes se comprometieron a trabajar y profundizar en las respuestas a los problemas provenientes del cambio climático en los países más vulnerables, en el marco del Mecanismo de Pérdidas y Daños, a través de la ampliación del ámbito de financiación del Fondo Verde, y se propusieron pactar un nuevo Plan de Género para dar respuesta al efecto desigual del cambio climático en las mujeres y niñas.

Otro aspecto a destacar de la COP 25 fue el papel protagonista que tuvo la dimensión social. Las discusiones reflejaron que en el centro de las respuestas a la crisis climática deben estar las personas, sus necesidades y su futuro. Y que afrontar este desafío es también avanzar hacia un modelo de prosperidad basado en la inclusión y en la equidad ${ }^{39}$.

Sin embargo, Carolina Schmidt, presidenta de la conferencia, calificó de insuficiente el acuerdo que cerró la COP 25. Sus palabras "no estamos satisfechos, los acuerdos no son suficientes para enfrentar con urgencia la crisis del cambio climático", evidencian lo mucho que tenemos que avanzar con respecto a la reducción de los principales contaminantes, entre ellos, el dióxido y el

\footnotetext{
37 ONU. Objetivos del Desarrollo Sostenible y Transformar nuestro mundo: la Agenda 2030 para el Desarrollo Sostenible, 2015 <http://www.un.org/sustainabledevelopment/es/2015/09/la-asamblea-general-adopta-la-agenda2030-para-el-desarrollo-sostenible/>y <http://www.un.org/es/comun/docs/?symbol=A/RES/70/1>.

${ }^{38}$ En 2000 se puso en marcha los Objetivos de Desarrollo del Milenio (ODM) ultimados en 2015 con ocho propósitos de desarrollo humano < https://www.undp.org/content/undp/es/home/sdgoverview/mdg_goals.html>. ${ }^{39} \mathrm{La}$ COP25 sienta las bases para que los países sean más ambiciosos ante la emergencia climática. Clausura de la Cumbre del Clima <https://www.miteco.gob.es/es/prensa/ultimas-noticias/la-cop25-sienta-las-bases-para-que-lospa\%C3\%ADses-sean-m\%C3\%A1s-ambiciosos-ante-la-emergencia-clim\%C3\%A1tica-/tcm:30505708\#: :text=La\%20cumbre\%20del\%20clima\%20(COP25,responder\%20a\%201a\%20emergencia\%20clim\%C3 $\%$ A1tica>.
} 
monóxido de carbono, el dióxido de azufre, el monóxido de nitrógeno, los clorofluorocarbonos y el metano.

Uno de los principales obstáculos de las negociaciones en la COP 25 fue el mercado del carbono, un mecanismo internacional para el intercambio (compra y venta) de derechos de emisión de dióxido de carbono entre empresas y países. Lo que estaba sobre la mesa del acuerdo era la institución de normativas en el Artículo 6 del Acuerdo de París que regulasen, de modo más efectivo, esta compensación.

Respecto a la disposición de los países en la lucha contra el cambio climático, lo que se constató en esta Cumbre es que mientras algunos gobiernos poseían un proyecto más ambicioso, como es el caso de la Unión Europea y otras naciones que la siguen de cerca, otros estados, como EE.UU., China, India y Rusia, grandes emisores, se desmarcaron o postergaron sus decisiones lo máximo posible.

Este es el escenario actual, dos décadas después de la firma del Protocolo de Kioto, que, a pesar de los compromisos firmados, evidencia un avance limitado. La contaminación continúa siendo un gran problema que algunos gobiernos no quieren reconocer. Es el caso del expresidente estadunidense Donald Trump que confirmó el 18 de agosto de 2019 su gran interés en comprar Groenlandia pensando en la exploración de sus reservas de minerales raros y también por su posición estratégica.

En función de estas dificultades para desarrollar políticas globales de control de la contaminación y de la degradación medioambiental, se observan algunas iniciativas de ámbito regional como es el Pacto Verde Europeo, una hoja de ruta para dotar a la Unión Europea de una economía sostenible hacia 2050, desde una transición integradora para todos ${ }^{40}$.

Expuestos los procedimientos de análisis del metabolismo socioeconómico originario del actual modelo de crecimiento exponencial, y señalados algunos de los principales obstáculos para poner en marcha políticas medioambientales globales, hacemos hincapié en la necesidad de desarrollar un entorno racional, armónico y justo, que suponga una vía hacia el 'decrecimiento', y a continuación, analizamos algunas propuestas hacia posibles alternativas para alcanzar su viabilidad.

\section{El decrecimiento como propuesta fundamental al cambio climático}

Ante lo expuesto, defender la continuidad del actual crecimiento económico exponencial, como lo han hecho varios economistas durante décadas, sin que para ello se tengan en cuenta los límites del ecosistema planetario, es ignorar la ley de la entropía, o creer que podemos rebasarla.

Esta 'racionalidad económica' basada en una economía lineal (producir, consumir y tirar en una espiral sinfín), ha ocasionado importantes crisis económicas. Éstas, han sido causadas por una sobreacumulación de capital, de sobreproducción, o de créditos hipotecarios (subprime) que, a la vez que posibilitan la "reconfiguración radical del desarrollo capitalista" ${ }^{41}$, dejan un importante

\footnotetext{
${ }^{40}$ Unión Europea <https://ec.europa.eu/info/strategy/priorities-2019-2024/european-green-deal_es>.

${ }^{41}$ Harvey, 2011, p. 37.
} 
contingente de la población sin víveres o sin hogares, mientras toneladas de alimentos se pudren en almacenes, o millares de viviendas son confiscadas por entidades hipotecarias.

Además, esta misma 'racionalidad económica' ha promovido, frente a su afán ilimitado de crear escenarios que incrementen los beneficios empresariales, el consumo indiscriminado de productos superfluos y el traslado de industrias altamente contaminantes a países con políticas medioambientales insuficientes, provocando la destrucción de gran parte de sus ecosistemas. También ha impulsado el capitalismo financiero volátil e intensificado los flujos de movilidad, lo que ha generado una situación de inestabilidad global, en la que las crisis (económicas, financieras o sanitarias) se desencadenan rápidamente en función de la gran dependencia espacio temporal de sus eslabones.

En esta dinámica compleja en la que lo local es global y lo global es local, reside una de sus principales contradicciones: el hecho de que el Estado, a pesar de haber tenido su papel reducido en las últimas décadas en sectores fundamentales como el económico y el de servicios esenciales (salud y educación), no solo socorra de las crisis a sus ciudadanos, sino también al capital, responsable de las mismas. La pandemia del Covid-19 nos demostró cómo la actuación del Estado fue y continúa siendo esencial para combatir la crisis sanitaria y sus consecuencias económicas ${ }^{42}$.

Este escenario deja claro que el modelo de desarrollo económico al que estamos sometidos, carece de cualquier sentido ético, ya que genera grandes desigualdades sociales y deja una profunda huella ecológica. El aumento de su principal índice, el PIB, no se traduce necesariamente en un incremento de bienestar de los individuos o colectivos. Tampoco lo es el PIB per cápita o ingreso per cápita, que solo podría ser válido como indicador de bienestar social si la distribución de la renta de un país fuera equitativa, lo que es casi imposible de lograr debido al modelo económico vigente.

A su vez, la tecnología, por si misma, no es una herramienta para resolver desequilibrios sociales, como los bajos salarios, el desempleo y la miseria. Ésta tampoco ha logrado resolver los límites que impone el proceso del reciclado en su totalidad, lo que hace inviable la reducción o la eliminación de la entropía, entendida como la magnitud física termodinámica que permite medir la parte no utilizable de la energía contenida en el sistema, o el grado de organización de un sistema.

En otras palabras, según Joaquín Sempere y Enric Tello, “estamos socavando el capital natural y, por lo tanto, vivimos a expensas del futuro"43.

Estos son algunos de los motivos por los que, creemos oportuno volver a un tema que ya tratamos anteriormente ${ }^{44}$, el 'decrecimiento' como una utopía necesaria.

\section{El decrecimiento como solución alternativa al actual paradigma económico}

Durante la década de 1970 se produjeron los primeros pasos para la elaboración de un concepto en el que el 'decrecimiento' se puso en el centro del debate. Las conclusiones de Nicholas Georgescu-Roegen revelaron la imposibilidad de un crecimiento infinito en un mundo finito y la

\footnotetext{
${ }^{42}$ Zaar, $2020<$ http://www.livrosabertos.sibi.usp.br/portaldelivrosUSP/catalog/book/552>.

${ }^{43}$ Sempere y Tello, 2007, p. 16.

${ }^{44}$ Zaar, 2018 <http://www.ub.edu/geocrit/Sociedad-postcapitalista/MiriamZaar.pdf >.
} 
necesidad de sustituir la ciencia económica tradicional por una bioeconomía que se situara en el seno de la biosfera ${ }^{45}$. A su vez, el Informe Meadows de 1972, actualizado y publicado en 1992 y 2004 subraya las consecuencias generadas por la demanda socioeconómica de las últimas décadas ${ }^{46}$.

En esta misma línea de pensamiento, y cuestionando el modelo de crecimiento ilimitado, aparecieron varios estudios. Entre ellos las reflexiones de Jorge Riechmann $(1996,2004)$ y de Jeremy Rifkin (2014) sobre crecimiento económico y entropía. Ambas coinciden en que las teorías económicas clásicas y neoclásicas no reconocen que son las leyes de la termodinámica, establecidas en el siglo XIX (por Sadi Carnot en 1824, y por Rudolf Clausius en 1865), las que rigen la actividad económica ${ }^{47}$.

Mientras las teorías económicas clásicas defienden que las dinámicas que rigen la biosfera terrestre no son más que simples externalidades para la actividad económica, las primera y segunda leyes de la termodinámica establecen otros criterios. La primera ley de la termodinámica establece que la materia-energía no se crea ni se destruye, solo se transforma; y la segunda ley de la termodinámica (conocida como principio de la entropía) defiende que, en un sistema cerrado, mientras la energía disponible tiende a decrecer, la energía utilizada (entropía) aunque no se haya perdido, se ha dispersado, lo que impide poder reutilizarla. En resumen: "La cantidad de energía permanece constante (por la primera ley); pero su calidad se degrada constantemente (por la segunda ley)" ${ }^{\prime 4}$.

\section{Según Rifkin:}

Las leyes primera y segunda de la termodinámica establecen que «la energía total en el universo es constante y la entropía total aumenta continuamente». La primera ley, la ley de la conservación, establece que la energía no se crea ni se destruye, que la cantidad de energía del universo siempre ha sido la misma desde el principio de los tiempos y lo seguirá siendo hasta el final. Pero, aunque la energía permanece constante, se transforma continuamente en una sola dirección, de disponible a no disponible. Aquí es donde entra en juego la segunda ley de la termodinámica según la cual la energía siempre fluye de lo caliente a lo frío, de lo concentrado a lo disperso, del orden al caos. Por ejemplo, si quemamos un trozo de carbón, la suma total de la energía no variará, pero esa energía se dispersará en la atmósfera en forma de dióxido de carbono, dióxido de azufre y otros gases. Aunque la energía no se ha perdido, el hecho de que se haya dispersado le impide producir un trabajo útil. Los físicos denominan entropía a esta energía que ya no se puede utilizar.

Toda actividad económica se basa en aprovechar la energía disponible en la naturaleza —en forma sólida, líquida o gaseosa- y convertirla en productos y servicios. En cada paso del proceso de producción, almacenamiento y distribución se utiliza energía para transformar recursos naturales en productos y servicios terminados. En la energía incorporada en cualquier producto o servicio se debe contar la energía utilizada y perdida - la factura entrópica - para «mover» la actividad económica a lo largo de la cadena de valor. Llegado el momento, los bienes que producimos se consumen, se desechan, se reciclan y se devuelven a la naturaleza con otro aumento de la entropía. Los ingenieros y los químicos señalan que, en relación con la actividad económica, nunca se produce un aumento neto de energía: siempre se produce una pérdida de la energía disponible en

\footnotetext{
${ }^{45}$ Georgescu-Roegen. The Entropy Law and the Economic Process, 1971.

${ }^{46}$ Meadows et al. Los límites del crecimiento, 2006.

${ }^{47}$ Riechmann, 1996, 2004; Rifkin, 2014.

${ }^{48}$ Riechmann, 1996, p. 8.
} 
el proceso de transformar los recursos naturales en valor económico. La gran pregunta es cuándo habrá que pagar la factura. Y la factura entrópica de la era industrial ya ha vencido ${ }^{49}$.

Esta coyuntura induce a Riechamnn a exponer cómo la economía ecológica, sitúa la segunda ley de la termodinámica en el centro de sus reflexiones. Partiendo de la premisa de que el proceso económico es entrópico en todas sus etapas materiales, lo que provoca importantes implicaciones económico-ecológicas, la segunda ley de la termodinámica muestra que la actividad económica está sometida por ciertos límites insuperables, como el del aprovechamiento total de los recursos naturales y el del reciclado en su totalidad. Asimismo, alude a los límites del crecimiento, debido a la imposibilidad de reducir o eliminar la entropía y también a los límites de la innovación tecnológica fijados por las leyes fundamentales de la naturaleza ${ }^{50}$.

Estas razones son las que Serge Latouche contempla cuando subraya que el crecimiento hoy en día solo es rentable económicamente a condición de que su peso recaiga sobre la naturaleza, sobre las generaciones futuras, sobre la salud de los consumidores y las condiciones del trabajo asalariado $^{51}$.

Teniendo en cuenta este contexto, Horacio Capel subraya la necesidad de un desarrollo de la economía como un proceso de suma cero, en el que pérdidas y ganancias se equilibrarían con exactitud: lo que se gana por un lado ha de proceder de lo que se pierde en otros ${ }^{52}$.

En medio de este debate surgen los conceptos que abarcan el término 'decrecimiento', y que representan, ante todo, una crítica y una voluntad de ruptura con el sistema económico actual y sus estrategias de acumulación. Sin embargo, aunque, el decrecimiento haya surgido con el propósito de impulsar una toma de conciencia hacia el modelo de desarrollo productivista, sus propósitos son mucho más amplios y comprenden un abanico de propuestas hacia una sociedad en la que el ser humano y la naturaleza puedan vivir armónicamente, ya que, como afirma Élisée Reclus, "el hombre es la naturaleza que adquiere consciencia de sí mismo"“53.

El politólogo Paul Ariés (2005) reconoce que el decrecimiento es un lema político con implicaciones teóricas, que busca romper el lenguaje estereotipado de los adictos al consumo; mientras que el economista Serge Latouche (2009), señala que el propósito principal de la consigna del decrecimiento es sobre todo apuntar a una clara renuncia al objetivo del crecimiento ilimitado, tal vez por esto convendría hablar de 'anticrecimiento'. Se trata, según el autor, de una propuesta para volver a abrir el espacio de la inventiva y de la creatividad de lo imaginario, bloqueado por el totalitarismo economicista ${ }^{54}$. Además, subraya, que no se trata de preconizar "decrecimiento por decrecimiento", lo que considera que sería absurdo.

En esta misma orientación, el ideólogo del movimiento francés para el decrecimiento, Vincent Cheynet, señala que la primera propuesta del decrecimiento no aspira a establecer un contrasistema ni una contra ideología en lugar de la ideología del crecimiento, sino a reinsuflar en

\footnotetext{
${ }^{49}$ Rifkin, 2014, p. 22-23. Según el autor toda actividad humana transforma recursos de 'baja entropía' (materiasprima y energías) en recursos de 'alta entropía' (materiales inutilizables- desechos y contaminación).

${ }^{50}$ Riechmann, 2004, capítulo 5.

${ }^{51}$ Latouche, 2009, p. 43.

${ }^{52}$ Capel, 2011 <http://www.ub.es/geocrit/b3w-930.htm>.

${ }^{53}$ Éliseé Reclus, 1985, p. 38-40.

${ }^{54}$ Latouche, 2009, p. 16-17.
} 
la sociedad el razonamiento crítico frente al pensamiento dogmático y los discursos propagandísticos ${ }^{55}$.

Pero hay otras propuestas que son más ambiciosas. Desde un análisis sobre la última crisis del capitalismo (2007-2008), el filósofo André Gorz señala que el decrecimiento es un imperativo de supervivencia, y que su puesta en marcha supone otra economía, otro estilo de vida, otra civilización y otras relaciones sociales ${ }^{56}$; y el ecologista francés Yves Cochet afirma que "el decrecimiento es nuestro destino obligado", habrá que prepararlo para que sea democrático y equitativo $^{57}$.

\section{¿Cómo lograr el decrecimiento?}

Para iniciar esta nueva posibilidad de evolución social, debemos, según Denis Bayon, Frabrice Flipo y François Schneider, "reencontrar en nosotros y fuera de nosotros nuestra naturaleza y todas las posibilidades que ella brinda, operar un cambio de identidad" ${ }^{18}$, porque, solo de este modo podremos comprender que el mundo que idealizamos no es una utopía, algo imposible, ya que reside en nuestra propia naturaleza.

El decrecimiento económico aspira a la transición hacia una sociedad ecológicamente sostenible, en la que el desarrollo no sería medido a través de la acumulación de bienes económicos y no tendría su principal indicador en el PIB, sino según otros criterios asociados a las necesidades básicas de los individuos, como alimentación saludable, educación, salud y preservación del ecosistema.

En virtud de ello, el lema del decrecimiento se propone captar las dimensiones de una situación nueva, en la que se torna esencial conjugar esfuerzos de instituciones públicas, de movimientos sociales y de la ciudadanía (concienciada y organizada), con el propósito de implantar otros valores distintos a los dominantes.

Esto es así, porque el decrecimiento es, ante todo, un proyecto político, social y económico en el que se establecería un modelo de educación, cuyas campañas informativas tendrían el propósito de formar un sentido crítico sobre los problemas vitales que el crecimiento económico ilimitado genera y las ventajas del proceso de decrecimiento.

Para ello, tornase esencial una educación que, asociada a programas de información, promoviera un cambio de actitudes respecto al consumo. El reconocimiento de la responsabilidad por los productos adquiridos y los residuos y desperdicios generados, estimularía nuevas formas de consumo, coherentes con los límites de la biosfera terrestre.

En esta misma línea, Lautoche pone énfasis en la necesidad de una revolución cultural, que debería desembocar en una refundación de lo político con la que se buscaría la coherencia teórica del conjunto, ya que el decrecimiento es un proyecto político de sociedades ahorradoras. Para ello, propone el círculo de las ocho ' $\mathrm{R}$ ': revaluar, reconceptuar, reestructurar, redistribuir, relocalizar,

\footnotetext{
${ }^{55}$ Cheynet, 2008 (Le choc de la décroissance). In Taibo, 2017, p. 93.

${ }^{56}$ Gorz, 2008, p. s/n.

${ }^{57}$ Dupin, $2009<$ http://www.rebelion.org/noticias/2009/8/90104.pdf >.

${ }^{58}$ Bayon, Flipo, Schneider, 2011, p. 53.
} 
reducir, reutilizar, reciclar ${ }^{59}$, y a partir del se podría comenzar con tres ' $\mathrm{R}$ ' prioritarias: reducir, reutilizar y reciclar.

En este proceso es imprescindible el estímulo a una economía circular ${ }^{60}$, en la que la sustitución del ciclo típico de la producción, utilización y descarte, por una mayor reutilización y reciclaje de los productos de consumo, lo que les daría una mayor vida útil, posibilitaría extraerles un mayor valor y disminuir los residuos.

Otro aspecto para alcanzar la 'vía del decrecimiento' es el incentivo al consumo de productos ecológicos de proximidad. Estimular la fabricación y elaboración de productos artesanales o manufacturados y el cultivo de alimentos libres de agrotóxicos está en consonancia con este nuevo modo de vida, planteado desde una relación respetuosa y amable entre el ser humano (y, por ende, la sociedad) y la naturaleza, incorporando otro atributo, la disminución del uso de combustibles reduciendo la contaminación atmosférica, debido a una logística de comercialización pautada en los transportes de corta y mediana distancia.

Del mismo modo, la praxis de la agricultura urbana y periurbana (AUP), reduce los impactos medioambientales y la creciente huella ecológica, constituyéndose en un importante instrumento a favor de la soberanía alimentaria, a la vez que contribuye a que las ciudades evolucionen hacia 'organismos saludables'. Su ejercicio hace viable: a) el acceso y la utilización de espacios intraurbanos y periurbanos sin edificar, lo que limita la acción del capital inmobiliario; b) el estímulo a las actividades que restablezcan las relaciones entre el hombre y la naturaleza y promuevan la integración y la complementariedad entre el campo y la ciudad, lo rural y lo urbano; c) incrementa la oferta y el consumo de productos locales, impulsando las practicas sostenibles y la autonomía laboral de grupos sociales con pocas posibilidades de incorporarse en el mercado de trabajo convencional; y, d) amplia los espacios de debate que suscitan una mayor concienciación de la comunidad local hacia una alimentación más saludable y acorde con la situación de emergencia climática en que vivimos, en la que debemos priorizar el consumo de vegetales (verduras y frutas de temporada, de proximidad, y si es posible ecológicas) en detrimento de los alimentos de origen animal, ya que la ganadería es uno de los grandes contaminantes de la atmósfera $^{61}$.

Las políticas gubernamentales de estímulo a la agricultura familiar y la agricultura urbana y periurbana (AUP) suponen una parte de la solución de los problemas relacionados con la insuficiencia alimentaria, con la calidad de los alimentos o con la degradación medioambiental provocada por los inputs agrícolas.

En esta nueva dinámica, el capital (principalmente vinculado a la tecnología de la automación), sería sustituido por el trabajo, y el monocultivo sería reemplazado por el policultivo, lo que reduciría la explotación de la fuerza laboral y de los recursos naturales. Así, las prácticas agrícolas sostenibles e integradas, organizadas en pequeñas y medianas explotaciones requerirían mayor trabajo humano y podrían contribuir a la repoblación de muchas regiones, en las que la mecanización de la agricultura expulsó a millares de agricultores familiares.

\footnotetext{
${ }^{59}$ Latouche, 2009, p. 36, 44-46.

${ }^{60}$ Se utilizó, por primera vez en 1980 el término "economía circular" (Pearce y Turner 1990) para describir un sistema cerrado de las interacciones entre economía y medio ambiente.

${ }^{61}$ Zaar, 2015, p. 42 <https://periodicos.ufrn.br/sociedadeeterritorio/article/view/7870/6137>.
} 
Se trata de proyectos e iniciativas organizados en circuitos cortos de reciprocidad que culminan en lo que Serge Lautoche subraya como la 'esencia del decrecimiento' y que proveen, igualmente, la 'relocalización' como programa político. Ésta, está argumentada en el hecho que, aunque el decrecimiento implique un pensamiento global, su actuación comenzaría localmente, a través de proyectos colectivos en biorregiones cuya realidad geográfica y social, facilitaría la capacidad de decisión y de acción coordinada y solidaria ${ }^{62}$.

Además, para alcanzar una economía de decrecimiento es esencial la implantación de políticas de transición hacia un sistema energético basado en tecnologías que impulsen las energías limpias, como las eólica, solar (fotovoltaica y térmica), geotérmica, mareomotriz, ola motriz, hidroeléctrica y el hidrógeno verde generado a partir de fuentes renovables. Con relación a las hidroeléctricas, solo se permitiría la construcción de pequeñas hidroeléctricas cuyo impacto social (anegación de tierras fértiles y desplazamiento de la población) y medioambiental (destrucción de ecosistemas, emisiones de gases de invernadero, etc.), fuera considerado nulo o muy reducido.

Vimos cómo la restricción de movilidad y la paralización de muchas actividades industriales, logísticas y de consumo de productos no esenciales durante la crisis de la pandemia de la Covid19 redujo sustancialmente la contaminación atmosférica tanto en China, cómo en Europa, EEUU, Brasil o India, mejorando sustancialmente la calidad de aire ${ }^{63}$. Las vías del decrecimiento proponen el desarrollo de políticas que estimulen la eficiencia energética residencial y comercial, y que fomenten el transporte público en detrimento del privado, ampliando su red y dotándole de más calidad y eficiencia; y a su vez, se gravaría onerosamente la utilización de energías y prácticas de actividades económicas contaminantes ${ }^{64}$.

En esta misma dirección, las administraciones públicas deberían priorizar, frente a la actual economía global, a la especulación inmobiliaria y al proceso de gentrificación que afecta a los barrios centrales de muchas ciudades turísticas ${ }^{65}$, una política de desarrollo de sus capacidades internas volcada al bienestar social, y a la vez gestionar proyectos de recuperación en los espacios degradados, que se pondrían en marcha con un diagnóstico específico y pormenorizado, teniendo en cuenta la memoria arquitectónica y ecológica del espacio a restaurar.

Estos planteamientos están en consonancia con el enfoque defendido por Edgar Morin en el que destaca que el objetivo del decrecimiento no está asociado solamente al desarrollo de los bienes materiales, la eficacia, la rentabilidad y la competitividad; sino a satisfacer las necesidades personales materiales e intelectuales, mediante aptitudes responsables con nuestros semejantes ${ }^{66}$ y nuestro entorno natural. Obviamente, sería diferente del actual desarrollo económico exponencial que fomenta el individualismo y la expropiación intensiva de nuestros recursos

\footnotetext{
62 Latouche, 2009, p. 58-60.

${ }^{63}$ Zaar y García Ávila, 2020. DOI: <https://doi.org/10.4000/espacoeconomia.10142>.

${ }^{64}$ La canciller alemana Angela Merkel anunció el 20 de septiembre de 2019, una serie de medidas con el objetivo de alcanzar para 2030 una reducción del 55\% de las emisiones de CO2, si comparado con los niveles de 1990. Para esto se estableció a) tasar a las emisiones de dióxido de carbono desde el origen a partir de 2021 y con subidas hasta 2026; b) bajar el precio del transporte ferroviario y subir el del transporte aéreo, c) subir, igualmente, las tasas para los vehículos más contaminantes; d) incentivar los vehículos eléctricos a través de la instalación de una red de carga en todo el país; e) fomentar la reforma de las viviendas para que consuman menos energía; f) fijar el fin del gasóleo en las calefacciones a partir de 2026 <https://www.rtve.es/noticias/20190920/alemania-anuncia-ambicioso-plan-54000millones-para-combatir-crisis-climatica/1979697.shtml>.

${ }^{65}$ Zaar, 2019b <http://www.ub.edu/geocrit/aracne/aracne-230.pdf>.

${ }^{66}$ Morin, 2011.
} 
naturales, sino un modelo pautado en el desarrollo social y económico endógeno y en una vivencia ética.

La fórmula del decrecimiento consiste, por lo tanto, de acuerdo con Serge Latouche en "hacer más y mejor con menos", lo que se puede lograr, según Edgar Morin, construyendo una 'Vía' que sustituya la hegemonía de la cantidad por la hegemonía de la calidad, la "obsesión de más por la obsesión de mejor"; y también, conforme el pensamiento de Paul Ariès, remplazando el disfrute del 'tener', por el disfrute del 'ser' 67 .

Aunque se trate de un planteamiento que en un principio tenga como objetivo la ruptura con el actual sistema económico de crecimiento ilimitado, las propuestas sugeridas, aplicadas de modo vinculante en procesos interdependientes, reúnen todos los requisitos para que se pueda poner en marcha una vía hacia el decrecimiento, proceso que reduciría la actual crisis ecológica y fomentaría la armonía entre el ser humano y la naturaleza. Un propósito apremiante, en función de las crisis sistémicas que padecemos periódicamente y del deterioro en que se encuentran nuestros ecosistemas y como corolario, el planeta Tierra.

\section{Bibliografía}

ARIÈS, Paul. Documental Decrecimiento. Entrevista, 2013 $<$ https://documentaldecrecimiento.com/2013/11/22/entrevista-a-paul-aries/>.

BAYON, Denis; FLIPO, Fabrice; SCHNEIDER, François. Decrecimiento. 10 preguntas para comprenderlo y debatirlo. Traducción de Julia Calzadilla. Barcelona: El Viejo Topo, 2011.

CAPEL, Horacio. Las ciudades, el consumo y el crecimiento de suma cero. Biblio 3W. Revista Bibliográfica de Geografía y Ciencias Sociales. [En línea]. Barcelona: Universidad de Barcelona, 5 de julio de 2011, Vol. XVI, no $930<$ http://www.ub.es/geocrit/b3w-930.htm>.

CAPEL, Horacio. Acción política y ciudadana para frenar el cambio climático. Biblio3W, Revista Bibliográfica de Geografía y Ciencias Sociales. Barcelona: Universidad de Barcelona, 5 de agosto de 2020, vol. XXV, no 1.303 <https://revistes.ub.edu/index.php/b3w/article/view/31671>

CASTRO MUÑOZ DE LUCAS, Manuel de. El cambio climático es una teoría científica. El País, 2/12/2015 <https://elpais.com/elpais/2015/12/01/opinion/1448991799_754191.html>.

CHAPAGAIN, A. K., HOEKSTRA, A.Y. Water footprints of nations. Value of Water Research. Report Series $\mathrm{n}^{\mathrm{0}} 16$, 2004. UNESCO-IHE. Delft, the Netherlands $<$ https://ris.utwente.nl/ws/portalfiles/portal/5132515/Report16Vol1MainReport.pdf>.

CRIPPA, M., GUIZZARDI, D., MUNTEAN, M., SCHAAF, E., DENTENER, F., van AARDENNE, JA, MONNI, S., DOERING, U., OLIVIER, JGJ, PAGLIARI, V., y JANSSENSMAENHOUT, G. Gridded emissions of air pollutants for the period 1970-2012 within EDGAR v4.3.2, 2018 Earth Syst. Sci. Datos, 10, 1987-2013 <https://www.earth-syst-scidata.net/10/1987/2018/>, <https://doi.org/10.5194/essd-10-1987-2018, 2018>.

\footnotetext{
${ }^{67}$ Latouche, 2009, p. 73; Morin, 2011, p. 89-90 y Paul Ariès, 2013, entrevista
} <https://documentaldecrecimiento.com/2013/11/22/entrevista-a-paul-aries/>. 
DIAMOND, Jared. Colapso. Por qué unas sociedades perduran y otras desaparecen. Barcelona: Debate, 2005 (edición original) y 2006 (edición española).

DUPIN, Eric. El decrecimiento ya no parece una locura. Informe Dipló, Le Monde Diplomatique, 2009. Traducción: Lucía Vera <http://www.rebelion.org/noticias/2009/8/90104.pdf>.

EUROPEAN COMISION. Emissions Database for Global Atmospheric Research (EDGAR) <https://edgar.jrc.ec.europa.eu/>

EUROPEAN COMISION. Acción por el Clima $<$ https://ec.europa.eu/clima/policies/international/negotiations/paris_es>.

FEARNSIDE, P.M.; PUEYO, S. Subestimação das emissões de gases de efeito estufa de represas tropicais. In FEARNSIDE, P. M. (ed.) Hidrelétricas na Amazônia: Impactos Ambientais e Sociais na Tomada de Decisões sobre Grandes Obras. Editora do INPA, Manaus, 2012, Vol. 2. p. 221226

<https://www.researchgate.net/publication/283153785_Subestimacao_das_emissoes_de_gases_ de_efeito_estufa_de_represas_tropicais/link/562d6e5108ae518e34824bf7/download>.

\section{BERKELEY EARTH. Global Temperature Report for 2019} <http://berkeleyearth.org/archive/2019-temperatures/>.

GOBIERNO DE ESPAÑA. MINISTERIO PARA LA TRANSICIÓN ECOLÓGICA. Plataforma Intergubernamental sobre Biodiversidad y Servicios Ecosistémicos (IPBES). <https://www.miteco.gob.es/es/biodiversidad/temas/conservacion-de-labiodiversidad/conservacion-de-la-biodiversidad-en-elmundo/cb_mundo_plataforma_ipbes.aspx>.

GOBIERNO DE ESPAÑA. La COP25 sienta las bases para que los países sean más ambiciosos ante la emergencia climática. Clausura de la Cumbre del Clima $<$ https://www.miteco.gob.es/es/prensa/ultimas-noticias/la-cop25-sienta-las-bases-para-que-lospa\%C3\%ADses-sean-m\%C3\%A1s-ambiciosos-ante-la-emergencia-clim\%C3\%A1tica-/tcm:30505708\#: :text=La\%20cumbre\%20del\%20clima\%20(COP25, responder\%20a\%20la\%20emerge ncia\%20clim\%C3\%A1tica>.

GORZ. André. La salida del capitalismo ya ha empezado. Ecorev, 2008/9, $\mathrm{n}^{\text {o }} 28,2$ <http://ecorev.org/spip.php?article640>.

FRIEDLINGSTEIN, Pierre et al. Global Carbón Budget 2020. Earth System Science Data, vol. 12, 2020. <https://essd.copernicus.org/articles/12/3269/2020/>. DOI: https://doi.org/10.5194/essd-12-3269-2020

GEORGESCU-ROEGEN, Nicholas. The Entropy Law and the Economic Process. Cambridge: Harvard University Press, 1971.

GLOBAL CARBON PROJECT. <https://www.globalcarbonproject.org/about/index.htm>, $<$ http://www.globalcarbonatlas.org/en/content/welcome-carbon-atlas >; $<$ https://www.globalcarbonproject.org/carbonbudget/archive.htm>. 
Global Footprint Network, 2021 Edition of the National Footprint and Biocapacity Accounts <https://www.footprintnetwork.org/>.

HARVEY, David. O enigma do capital e as crises do capitalismo. São Paulo: Boitempo, 2011.

HARVEY, David. Diecisiete contradicciones del capital. Quito: Editorial IAEN, 2014. Traducción: Juan Mari Madariaga. Madrid: Traficante de los Sueños, 2014 <https://www.traficantes.net/sites/default/files/pdfs/Diecisiete\%20contradicciones\%20-

$\% 20$ Traficantes\%20de\%20Sue\%C3\%B1os.pdf $>$.

HOEKSTRA, A. Y. Virtual Water. An Introduction. Virtual Water Trade. Proceedings of the International Expert Meeting on Virtual Water Trade. Values of Water Research Report Series $\mathrm{n}^{\circ}$ 12, 2003. IHE, Delft, Holanda <https://waterfootprint.org/media/downloads/Report12.pdf>.

INFORME PLANETA VIVO. 2018: Apuntando más alto. <http://awsassets.wwf.es/downloads/informe_planeta_vivo_2018.pdf?_ga=2.80222672.6994986 45.1563707033-1726489900.1561834853>.

INTERGOVERNMENTAL PANEL ON CLIMATE CHANGE (IPCC) <https://archive.ipcc.ch/home_languages_main_spanish.shtml>, <https://ar5syr.ipcc.ch/topic_summary.php>, <https://www.miteco.gob.es/es/ceneam/recursos/miniportales-tematicos/Cclimatico/informe_ipcc.aspx $>$

JCR Science Police for Report. Fossil $\mathrm{CO}^{2}$ emissions of all countries. Report 2020 <https://edgar.jrc.ec.europa.eu/booklet2020/Fossil_CO2_emissions_of_all_world_countries_bo oklet_2020report.pdf>.

LATOUCHE, Serge. Pequeño tratado del decrecimiento sereno. Barcelona: Icaria, 2009.

MEADOWS, Donella; RANDERS, Gorgen; MEADOWS, Dennis. Los límites del crecimiento, Barcelona: Galaxia Guterberg, 2006.

MORIN, Edgar. La vía para el futuro de la humanidad. Barcelona, Buenos Aires y México: Paidós, 2011.

NATIONAL GEOGRAPHIC ESPAÑA. 11 formas de ver cómo el Cambio Climático amenaza el Ártico <https://www.nationalgeographic.com.es/ciencia/actualidad/formas-ver-como-cambioclimatico-amenaza-artico_11272/1>.

NASA. GISS Surface Temperature Analysis

<https://data.giss.nasa.gov/gistemp/graphs_v4/>.

ONU. Objetivos de Desarrollo del Milenio (ODM) ultimados en 2015 con ocho propósitos de desarrollo humano <https://www.undp.org/content/undp/es/home/sdgoverview/mdg_goals.html>.

ONU. Objetivos del Desarrollo Sostenible y Transformar nuestro mundo: la Agenda 2030 para el Desarrollo Sostenible, 2015 <http://www.un.org/sustainabledevelopment/es/2015/09/laasamblea-general-adopta-la-agenda-2030-para-el-desarrollo-sostenible/>. 
PEARCE, David W.; TURNER, Robert K. Economics of natural resources and the environment. Brighton: Harvester Wheats, 1990.

RECLUS, Élisée. O Homem é a natureza adquirindo consciência de si própria. In FERNANDES, Florestan y ANDRADE, Manuel Correia. Élisée Reclus. São Paulo: Editora Ática, 1985. p. 3840. Título original: Préface. L'homme est la nature prenant conscience d'elle-mêsme. L'homme et la Terre, tomo I.

RIECHMANN, Jorge. Por qué los muertos no resucitan y el reciclado perfecto es imposible. Ecología, economía y termodinámica. FERNÁNDEZ BUEY, Francisco; RIECHMANN, Jorge. Ni tributos. Ideas y materiales para un programa ecosocialista. Madrid: Siglo XXI, 1996.

RIECHMANN, Jorge. Ciencia, tecnología y sustentabilidad. RIECHMANN, Jorge. Gente que no quiere viajar a Marte. Ensayos sobre ecología, ética y autolimitación. Madrid: Los Libros de la Catarata, 2004.

RIFKIN, Jeremy. La sociedad de coste marginal cero. El Internet de las cosas, el procomún colaborativo y el eclipse del capitalismo. Barcelona: Espasa Libros, 2014.

RTVE.es. Alemania lanza un ambicioso plan de 54.000 millones para combatir la crisis climática <https://www.rtve.es/noticias/20190920/alemania-anuncia-ambicioso-plan-54000-millonespara-combatir-crisis-climatica/1979697.shtml>.

SCIENCE AND POLICE OF PEOPLE AND NATURE (IPBES). <http://www.creaf.uab.cat/fotosprensa/Nota_Premsa_IPBES_2018.pdf >.

SEMPERE, Joaquim; TELLO, Enric. El final de la era del petróleo barato. Barcelona: Icaria, 2007.

TAIBO, Carlos. En defensa del decrecimiento. Madrid: Los libros de la Catarata, 2017.

TOLEDO. Víctor. El metabolismo social: una nueva teoría socioecológica. Relaciones 136, otoño 2013, p. 41-71 <http://www.scielo.org.mx/pdf/rz/v34n136/v34n136a4.pdf>.

UNESCO-IHE. Institute for Water Education. National water footprint accounts: The green, blue and grey water footprint of production and consumption. Volume I Main Report, 2011 <https://waterfootprint.org/media/downloads/Report50-NationalWaterFootprints-Vol1.pdf>.

UNIÓN EUROPEA. Un Pacto Verde Europeo <https://ec.europa.eu/info/strategy/priorities-20192024/european-green-deal_es>.

VENGOECHEA, Alejandra de. Las Cumbres de las naciones Unidos sobre Cambio Climático. <https://library.fes.de/pdf-files/bueros/la-energiayclima/09155.pdf>, $<$ http://www.un.org/es/comun/docs/?symbol=A/RES/70/1>.

WACKERNAGEL, Mathis et al. National natural capital accounting with the ecological footprint concept. Ecological Economics 29, 1999, p. 375-390<http://metagraphies.org/Sir-PatrickGeddes/ecology/Wackernagel_National.pdf >. 
WORLD CLIMATE RESEARCH PROGRAMME <https://www.wcrp-climate.org/>.

World Wildlife Fund (WWF) <https://www.wwf.es/nuestro_trabajo_/informe_planeta_vivo/>.

ZAAR, Miriam Hermi. A Agricultura Urbana e Periurbana no marco da soberania alimentar. Sociedade e Território. Natal, RN: UFRN, julio/diciembre de 2015, Vol. 27, nº 3, p. 26-44 <https://periodicos.ufrn.br/sociedadeeterritorio/article/view/7870/6137>.

ZAAR, Miriam Hermi. Del decrecimiento al post-capitalismo. In ZAAR, Miriam; CAPEL, Horacio (Coords. y eds.). Las ciencias sociales y la edificación de una sociedad post-capitalista. Barcelona: Universidad de Barcelona/Geocritica, 2018 <http://www.ub.edu/geocrit/Sociedadpostcapitalista/MiriamZaar.pdf>.

ZAAR, Miriam-Hermi. Gentrificación y turismo urbano. ¿Cómo se articulan?Ar@cne. Revista Electrónica de Recursos de Internet sobre Geografía y Ciencias Sociales. Barcelona: Universidad de Barcelona, $\mathrm{n}^{\mathbf{o}}$ 230, 1 de febrero de 2019 <http://www.ub.edu/geocrit/aracne/aracne-230.pdf > (a).

ZAAR, Miriam-Hermi. Política energética brasileña. Las grandes hidroeléctricas y sus impactos medioambientales y sociales. In CAPEL, Horacio; ZAAR, Miriam (Coords. y Eds.). La electricidad y la transformación de la vida urbana y social. Barcelona: Universidad de Barcelona/Geocrítica, 2019 <http://www.ub.edu/geocrit/Electricidad-y-transformacion-de-lavida-urbana/MiriamZaar.pdf $>$ (b).

ZAAR, Miriam Hermi; GARCÍA ÁVILA, Manuel-Blas. El Covid-19 en España y sus primeras consecuencias, Espaço e Economia [Online], $17 \mid 2020, \quad 06 \quad$ abril. DOI: $<$ https://doi.org/10.4000/espacoeconomia.10142>.

ZAAR, Miriam Hermi. A geografia da crise Covi-19 na União Europeia. RIBEIRO, Wagner Costa (Org.) Covid-19: passado, presente e futuro. São Paulo: FFLCH/USP, 2020. $<$ http://www.livrosabertos.sibi.usp.br/portaldelivrosUSP/catalog/book/552> DOI: <https://doi.org/10.11606/9786587621319>.

Ficha bibliográfica:

ZAAR, Miriam Hermi. Cambio climático antropogénico y decrecimiento. Ar@cne. Revista Electrónica de Recursos de Internet sobre Geografia y Ciencias Sociales. Barcelona: Universidad de Barcelona, I de enero de 2021, vol. XXV, n 250. DOI: https://doi.org//0.1344/ara2021.250.33232 